Article

\title{
Dynamic Simulations of Adaptive Design Approaches to Control the Speed of an Induction Machine Considering Parameter Uncertainties and External Perturbations
}

\author{
Kamran Zeb 1,2 (1), Waqar U. Din ${ }^{1}$ (1) , Muhammad Adil Khan ${ }^{3}$, Ayesha Khan ${ }^{4}$, Umair Younas ${ }^{5}$, \\ Tiago Davi Curi Busarello ${ }^{6}$ (D) and Hee Je Kim ${ }^{1, *}$ \\ 1 School of Electrical Engineering, Pusan National University, San 30, ChangJeon 2 Dong, Pusandaehak-ro 63 \\ beon-gil 2, Geumjeong-gu, Busan 46241, Korea; kami_zeb@yahoo.com (K.Z.); waqudn@pusan.ac.kr (W.U.D.) \\ 2 School of Electrical Engineering and Computer Science, National University of Sciences and Technology, \\ Islamabad 44000, Pakistan \\ 3 Department of Electrical and Computer Engineering, Air University Islamabad 44000, Pakistan; \\ adil.khan@mail.au.edu.pk \\ 4 Department of Electrical Engineering University of Management and Technology, Sialkot 51040, Pakistan; \\ ieesha_tanoli@yahoo.com \\ 5 Department of Electrical Engineering, Selçuk University Konya 42100, Turkey; umair.ciitatd@gmail.com \\ 6 Department of Engineering, Federal University of Santa Catarina Blumenau, Rua João Pessoa \\ 2750-89036-256, Brazil; tiago.busarello@ufsc.br \\ * Correspondence: heeje@pusan.ac.kr; Tel.: +82-10-3462-1990
}

Received: 3 August 2018; Accepted: 3 September 2018; Published: 5 September 2018

\begin{abstract}
Recently, the Indirect Field Oriented Control (IFOC) scheme for Induction Motors (IM) has gained wide acceptance in high performance applications. The IFOC has remarkable characteristics of decoupling torque and flux along with an easy hardware implementation. However, the detuning limits the performance of drives due to uncertainties of parameters. Conventionally, the use of a Proportional Integral Differential (PID) controller has been very frequent in variable speed drive applications. However, it does not allow for the operation of an IM in a wide range of speeds. In order to tackle these problems, optimal, robust, and adaptive control algorithms are mostly in use. The work presented in this paper is based on new optimal, robust, and adaptive control strategies, including an Adaptive Proportional Integral (PI) controller, sliding mode control, Fuzzy Logic (FL) control based on Steepest Descent (SD), Levenberg-Marquardt (LM) algorithms, and Hybrid Control (HC) or adaptive sliding mode controller to overcome the deficiency of conventional control strategies. The main theme is to design a robust control scheme having faster dynamic response, reliable operation for parameter uncertainties and speed variation, and maximized torque and efficiency of the IM. The test bench of the IM control has three main parts: IM model, Inverter Model, and control structure. The IM is modelled in synchronous frame using $d q$ modelling while the Space Vector Pulse Width Modulation (SVPWM) technique is used for modulation of the inverter. Our proposed controllers are critically analyzed and compared with the PI controller considering different conditions: parameter uncertainties, speed variation, load disturbances, and under electrical faults. In addition, the results validate the effectiveness of the designed controllers and are then related to former works.
\end{abstract}

Keywords: induction motor; indirect field oriented control; PI controller; adaptive PI controller; fuzzy logic controller; sliding mode controller; adaptive sliding mode controller; space vector pulse width modulation 


\section{Introduction}

Induction Machines (IM) have a wide use in industries for different processes due to their high performance. Since their discovery, the IM has been considered the predominant actuator in constant speed maneuvers. The advantageous characteristics of IM are: (a) low cost, (b) high efficiency, (c) small inertia, (d) inherent self-starting, (e) absence of collector brooms systems, (f) less maintenance, and (g) simpler design [1]. Conversely, the IM is insufficient to provide flexible speed operation due to its non-linear, complex, and multivariable mathematical model [2]. The aforementioned limitations can be resolved by designing smart and sophisticated Vector Control (VC) and scalar control strategies [3].

Remarkable dynamic response is mandatory for the load disturbances and parameter uncertainties of electric drives to respond to speed and torque control loops. In scalar control, constant torque and flux response is achieved by simple a $\mathrm{V} / \mathrm{f}$ or Volts/Hertz constant rule with the sluggish dynamic response. In the greater part of advanced, industrial electrical-drive control-applications, the standardized technique to control squirrel cage induction motors is based on the VC principle to accomplish the best dynamic performance [3,4]. In VC or Field-Oriented Control (FOC), like a separately excited DC motor, the flux and torque are individually controlled [5]. The addition of VC to IM lead to IM popularity by allowing variable speed operation and motion control drives [6]. The speed, torque, and position of the IM are conventionally controlled by a fixed gain Proportional Integral Differential (PID) control strategy that is load, speed, and parameter variation disturbance-sensitive. Adaptive control law is one of the solutions to solve these problems [7].

Recently, specialists have centered their effort on mitigating the effect of uncertainties and disturbances using various control approaches. The PID control scheme is widely utilized in industries because of the ease of design, low cost, and simple control structure [8]. However, this scheme is unable to provide perfect control for uncertainty, disturbances, and highly non-linear systems. In addition, these control schemes lack the knowledge of uncertainty and disturbances. However, non-linear control is used to tackle the parameter variation problem and enhance the performance of Indirect Field Oriented Control (IFOC) IM. These control methods include adaptive and robust control [9,10], variable structure control [11], Sliding Mode Control (SMC) [12,13], Fuzzy Logic Control (FLC) [14,15], Neural Network (NN) [16,17], Hybrid Controller (HC) [18], a genetic algorithm based on supervisory control [19], Model Reference Systems (MRAS) control [20], and optimal control [21] strategies. The above-mentioned non-linear control techniques improved control performance of the IM. Though, these linear and non-linear control strategies lack analysis of load disturbances, parameter uncertainties due to inductances and temperature, and speed variation in comparison with various optimal and adaptive control strategies. Moreover, electrical fault perturbation investigation, e.g., double phase, single phase, overvoltage, and undervoltage, has not been incorporated in previous work done on IFOC IM drives [22-25].

This paper is based on the design of the following different optimal control strategies: (a) FLC based on Steepest Descent (SD) and Levenberg-Marquardt (LM) algorithms (b) adaptive Proportional Integral (PI) control (c) SMC, and (d) HC or adaptive SMC for compensation of parameter uncertainties, load disturbances, electrical faults perturbations, and speed variation of IFOC IM. The Adaptive PI control scheme incorporates the promising features of conventional PI and Fuzzy Logic. The Fuzzy Inference System (FIS) is used to update proportional $k_{p}$ and integral $k_{i}$ gains in accordance with sudden load disturbances, parameter uncertainties, and speed variations. The proposed control design provides better and faster dynamic response with a zero Steady State Error (SSE) [22].

The presence of parameter uncertainties, load disturbance, and temperature variation makes the accomplishment of an exact model challenging. To tackle such deficiencies, FLC is implemented in the IM drives, as FLC does not require an exact mathematical model as it adds human logical thinking to the control scheme [14]. The FLC uses a linguistic approach for developing a control algorithm for the Multiple Input Multiple Output (MIMO) system by mapping the output and the input correlation based on human proficiency. The global non-linearities that are mostly problematic to the model are controlled by Fuzzy logics that makes FLC tolerable to parameter uncertainties, robust, and more 
accurate [15]. The valuable features of the proposed SMC are as follows: (a) it is insensitive to external load disturbance and robust to system uncertainties and parameter variation, (b) it offers a stable control system with faster dynamic response, (c) the software/hardware implementation of SMC is easy, and (d) the non-linear systems that are uncontrollable with linear controllers are handled by SMC $[12,13]$. In our designed HC, the better of the two non-linear control approaches, PI-fuzzy and SMC, are incorporated. PI-fuzzy reduces chattering during steady state operation. The transient state error is minimized by SMC, providing system stability and fast dynamic response [23].

In light of the above specified issues, the main contributions of our paper are:

- Our proposed control schemes are based on: (a) Fuzzy PI, (b) Fuzzy based on Levenberg Marquardt (LM) and Steepest Descent techniques, (c) Sliding Mode (SM), and (d) HC based on fuzzy PI and sliding mode principles for an IFOC IM drive.

- Superior Space Vector Pulse Width Modulation (SVPWM) technique-based inverter is designed. The dominant features of the SVPWM are: (a) low switching losses, (b) lower ripples, (c) simple digital implementation, (d) constant switching frequency, and (f) maximum DC-bus voltage utilization.

- The performance of the detuning effect of the IFOC caused by Rotor Resistance (RR) deviation at $200 \%, 150 \%$, and $120 \%$ of the rated values are analyzed for proposed optimal control schemes.

- Electrical faults perturbations, e.g., double phasing, single phasing, overvoltage, and undervoltage, are scrutinized along with load disturbances in order to verify robustness and fault tolerant capability of the IFOC IM drive.

- Comparative analyses of the various proposed optimal control strategies for load disturbances concerning undershoot, overshoot, rise time, settling time, and fast response with traditionally tuned PI controller are also performed.

- Speed variation is also discussed, described, and analyzed to satisfy the requirement of variable speed drives.

The rest of paper is organized as follows: the modeling of IM in a synchronous frame is described in Section 2, Section 3 presents the IFOC schemes for the IM, and the design of different proposed controlled strategies is presented in Section 4. Section 5 shows the assessment and comparison of different control strategies and finally Section 6 concludes the paper and suggests future directions.

\section{Modelling of IM in a Synchronous Reference Frame}

The mathematical model of a three phase Y-connected squirrel cage IM in direct quadrature $(d q)$-synchronous rotating reference frame is specified by the subsequent equations [24].

\subsection{Stator Model}

The stator $d q$-axis voltages with corresponding flux linkages and currents are described as:

$$
\begin{aligned}
& v_{s d}=R_{s} i_{s d}-\omega_{d} \lambda_{s q}+L_{l s} \frac{d}{d t} i_{s d}+L_{m} \frac{d}{d t}\left(i_{s d}+i_{r d}\right) \\
& v_{s q}=R_{s} i_{s q}+\omega_{d} \lambda_{s d}+L_{l s} \frac{d}{d t} i_{s q}+L_{m} \frac{d}{d t}\left(i_{s q}+i_{r q}\right)
\end{aligned}
$$

where $R_{s}$ and $R_{r}$ are stator and rotor resistances, respectively. $v_{s d}$ and $v_{s q}$ are synchronous frame and stator ( $d q$-axis) voltages, respectively. $\lambda_{s d}$ and $\lambda_{s q}$ are synchronous frame and stator ( $d q$-axis) fluxes, respectively. $i_{s d}$ and $i_{s q}$ synchronous frame and stator ( $d q$-axis) currents, respectively. $\omega_{d}$ is synchronous electrical speed and $L_{m}$ is mutual inductance.

\subsection{Rotor Model}

The rotor $d q$-axis voltages with corresponding flux linkages and currents are stated below 


$$
\begin{aligned}
& \underbrace{v_{r d}}_{\text {equal to } 0}=R_{r} i_{r d}-\omega_{d A} \lambda_{r q}+L_{l r} \frac{d}{d t} i_{r d}+L_{m} \frac{d}{d t}\left(i_{s d}+i_{r d}\right) \\
& \underbrace{v_{r q}}_{\text {equal to } 0}=R_{r} i_{r q}+\omega_{d A} \lambda_{r d}+L_{l r} \frac{d}{d t} i_{r q}+L_{m} \frac{d}{d t}\left(i_{s q}+i_{r q}\right)
\end{aligned}
$$

In the above equations, all parameters are the same as previously stated, only subscript " $s$ " is replaced with subscript " $r$ " for rotor and $\omega_{d A}$ is angular slip speed.

The stator and rotor model Equations (1)-(4), are combined to describe the $d q$ equivalent circuits for the $d$-axis and $q$-axis in Figure 1.

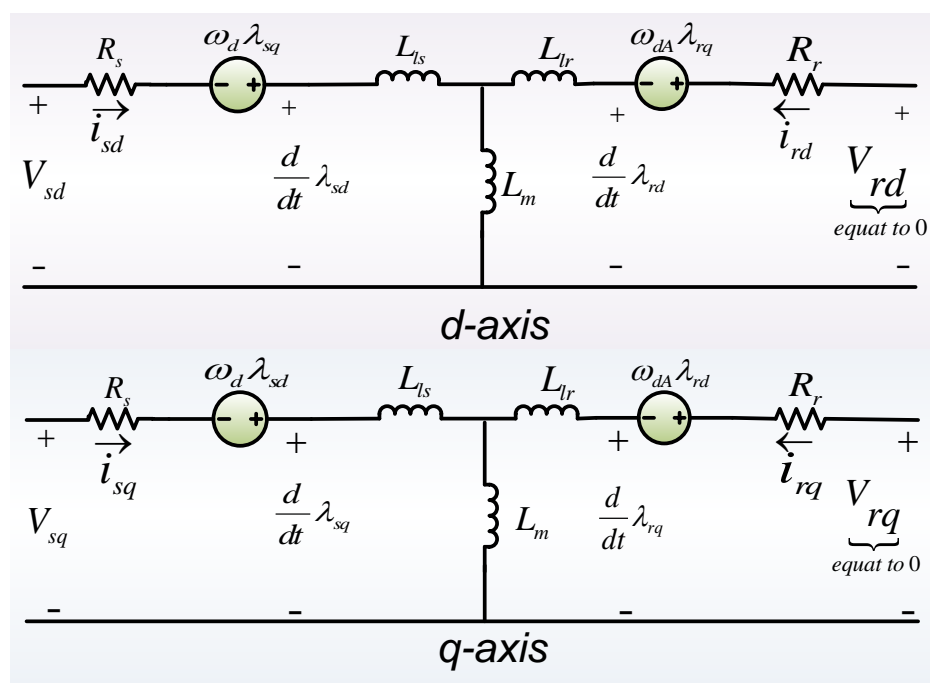

Figure 1. The $d q$ equivalent circuits of the induction motor (IM).

\subsection{Rotor Electromagnetic Torque}

The instantaneous electromagnetic torque $T_{e m}$ acting on the $d$-axis and the $q$-axis of the rotor can be written by superposition as follows:

$$
T_{e m}=T_{d, \text { rotor }}+T_{q, \text { rotor }}
$$

Equation (5), with corresponding inductance and $d q$-axis currents, is formulated as:

$$
T_{e m}=\frac{p}{2} L_{m}\left(i_{s q} i_{r d}-i_{s d} i_{r q}\right)
$$

\subsection{Electrodynamics of IM}

Subtraction of load torque $T_{L}$ from electromagnetic torque $T_{e m}$ acting on the moment of inertia $J_{e q}$ determines the acceleration as presented in Equation (7a). In addition, Equation (7a) also demonstrates the mechanical part of the motor $[5,24]$. Whereas, Equation $(7 \mathrm{~b})$ describes the actual mechanical speed of the rotor in radians per second as:

$$
\begin{gathered}
\frac{d}{d t} \omega_{m e c h}=\frac{T_{e m}-T_{L}}{J e q}=\frac{\frac{p}{2} L_{m}\left(i_{s q} i_{r d}-i_{s d} i_{r q}\right)-T_{L}}{J_{e q}} \\
\omega_{m}=p / 2 \omega_{\text {mech }}
\end{gathered}
$$




\section{Field Oriented Control Schemes}

The VC scheme has the remarkable advantage of decoupling the flux and torque. It makes AC drives equivalent to DC drives with superior dynamic response in high-performance applications. In the VC strategy, the position of the rotor flux linkages $\lambda_{r}$ is assumed at an angle $\theta_{f}$ from the stationary reference frame. Where $\theta_{f}$ is the field angle that is used to calculate currents of the $d q$-axis in a synchronous reference frame via three phase stator currents through transformation. The stator current yields the rotor flux $\lambda_{r}$ and the electromagnetic torque $T_{e}$, as presented in Figure 2. Moreover, in Figure 2 the stator current vector is resolved along $\lambda_{r}$, horizontally generates field producing component $i_{f}$, and vertically provides torque controlling component $i_{T}$. Controlling only the field current controls the rotor flux linkages just like a separately-excited DC machine. In the DC motor, the field current controls the field flux with no impact of armature current. The flux is controlled by the $d$ component of the stator current based on the equation:

$$
i_{s d}=f\left(\lambda_{r}, i_{f}\right)
$$

Similarly, controlling torque generating current $i_{T}$ at constant rotor flux linkages, independently controls electromagnetic torque, just like electromagnetic torque is controlled by armature current in a separately excited DC machine [5], described as:

$$
T_{e} \propto \lambda_{r} i_{T} \propto i_{f} i_{T}
$$

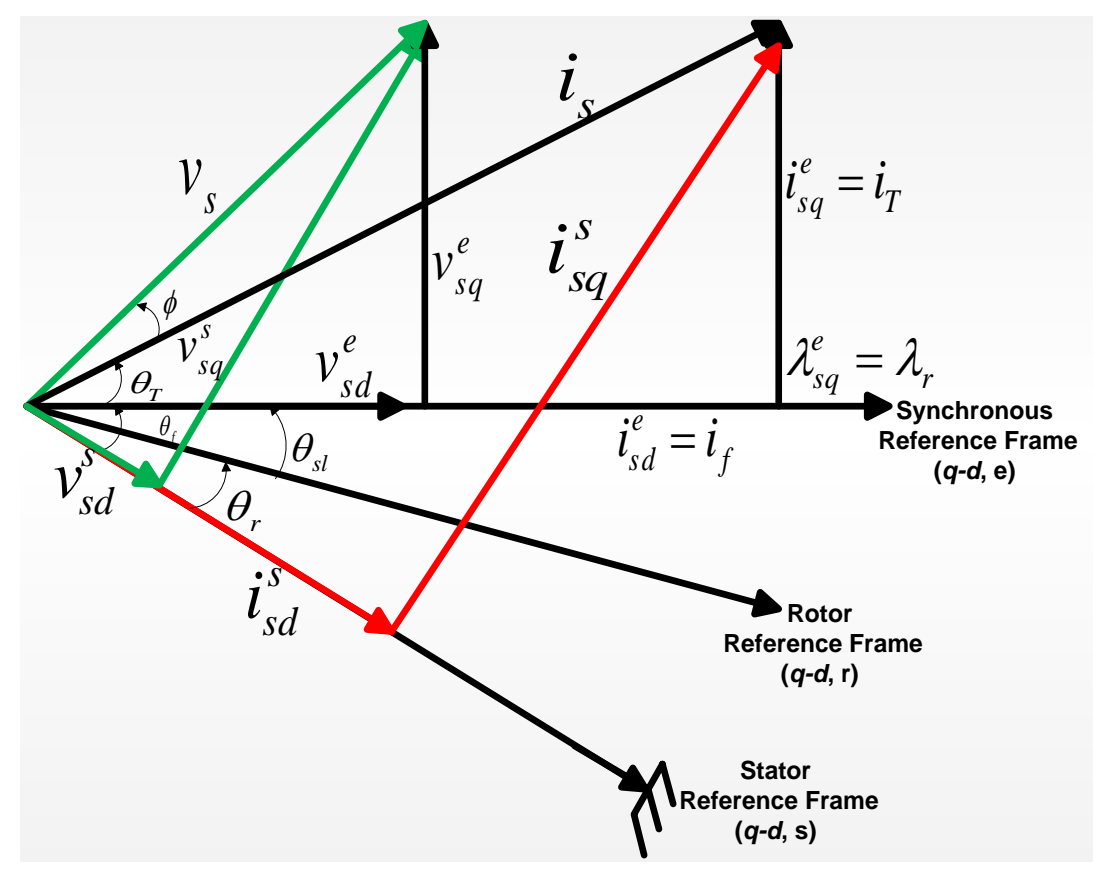

Figure 2. Indirect Field Oriented Controller Phasor Diagram [24,25].

The instantaneous rotor flux locus, $\theta_{f}$, is defined as:

$$
\theta_{f}=\theta_{r}+\theta_{s l}
$$

where $\theta_{r}$ is the rotor is angle and $\theta_{s l}$ is the slip angle. The $\theta_{f}$ is formulated as:

$$
\theta_{f}=\int\left(\theta_{r}+\theta_{s l}\right) d t=\int \omega_{s} d t
$$




\subsection{Field Oriented Control Scheme: A Taxonomy Overview}

Field oriented control scheme on the basis of field angle acquisition is classified into two subcategories. If the field angle $\theta_{f}$ is determined by using Hall sensors or terminal currents and voltages or flux-sensing windings, then it is recognized as a Direct Field Oriented Control (DFOC) scheme. When the field angle is calculated by utilizing the position of the rotor and partial estimation with only machine parameters, without using additional variables, e.g., voltages and currents, it is called an IFOC scheme [24,25]. Figure 3 depicts the classification of Field Oriented Control Schemes (FOCS) for IM [9]. Furthermore, this research is based on estimated field angle.

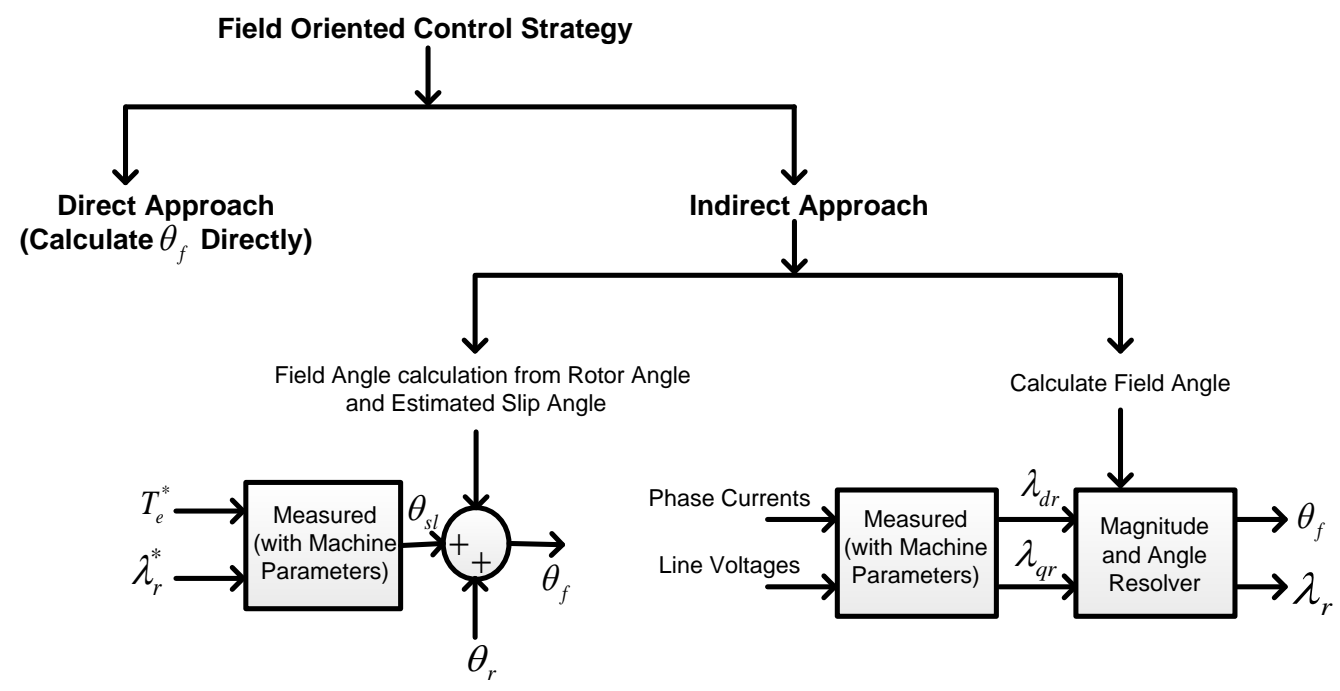

Figure 3. Classification of the Field Oriented Control Scheme [24,25].

\subsection{Implementation of Indirect Field Oriented Control Scheme}

The indirect FOCS is advantageous over direct FOCS due to its remarkable features like (a) reluctance to Hall effect and flux sensors (b) reduced number of transducer and feedback loops, and (c) tranquil operation at zero speed and near zero speed [5]. The indirect FOCS is derived from a dynamic equation of the IM in the synchronous revolving reference frame. For simplicity, a current source-inverter is supposed that serves the stator phase current as an input and is neglected for further consideration. The IFOC scheme is derived in detail in [24]. In an indirect FOCS, the flux linkage of rotor winding is aligned on the $d$-axis, which gives $\lambda_{r}=\lambda_{r d}, \lambda_{r q}=0$, and $\frac{d}{d t} \lambda_{r q}=0$ [24] and modifies the slip equation below:

$$
\omega_{s l}=\left[\frac{L_{m i_{s q}}}{T_{r} \lambda_{r}}\right]
$$

Equation (9) calculates slip speed. Where $T_{r}=\frac{L_{r}}{R_{r}}$ is the rotor's time constant. The rotor flux equation related to $i_{s d}$ is presented as:

$$
\lambda_{r}(s)=\frac{L_{m}}{\left(1+s T_{r}\right)} i_{s d}(s)
$$

Equation (10), provides the reliance of $\lambda_{r}$ on $i_{s d}$ and is known as the dynamics equation of the $d$-axis rotor flux linkage. The $T_{e m}$ is generated by the rotor $d$-axis flux, which is acting on the rotor $q$-axis winding, while the $q$-axis rotor flux is zero, established as:

$$
T_{e m}=\frac{p}{2} \lambda_{r}\left(\frac{L_{m}}{L_{r}} i_{s q}\right)
$$


Figure 4 depicts, the model of IM for field angle $\theta_{f}$ calculation, basically, this is the implementation of Equations (9)-(11). The flux linkage of the rotor $\lambda_{r}$ is aligned with the $d$-axis. The rotor flux $\lambda_{r}$, field angle $\theta_{f}$ and electromagnetic torque $T_{e m}$ can be obtained from $i_{s d}, i_{s q}$, and $\omega_{m e c h}$ as inputs.

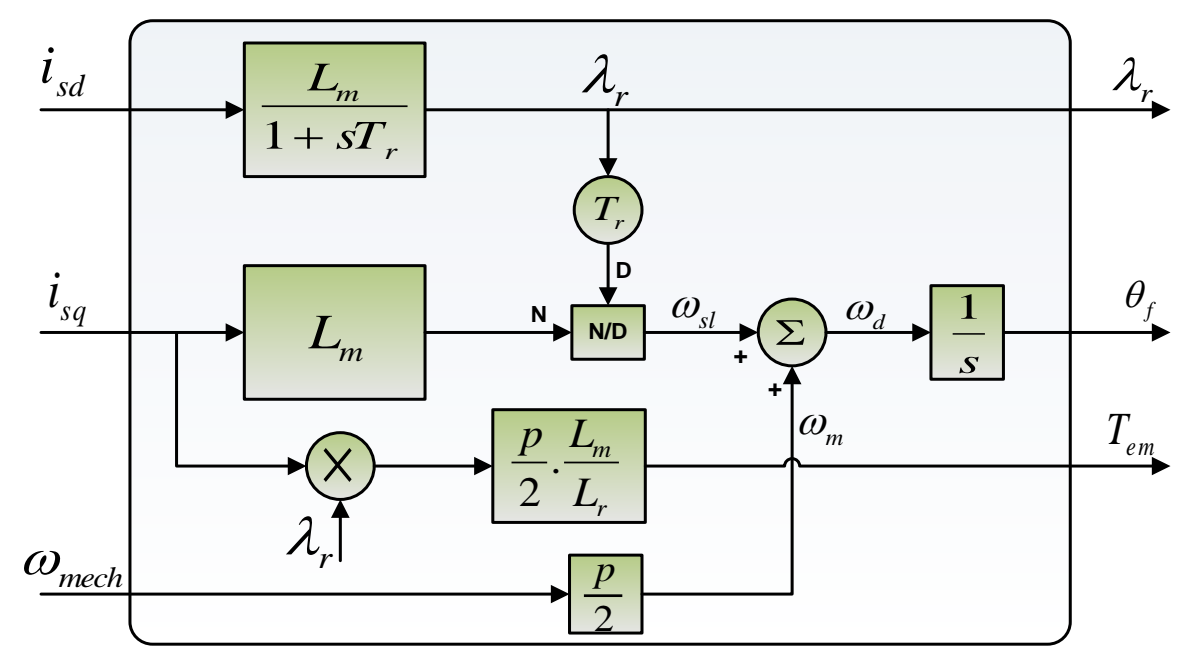

Figure 4. The estimated model for $\theta_{f}$ calculation.

\subsection{Proposed System Model of Indirect Field Oriented Control}

Figure 5 depicts the block diagram of the indirect VC scheme (VCS) or IFOC IM based on the proposed controllers. The machine drive applies indirect FOCS to IM, while the switches of the inverter are operated by the SVPWM technique. The calculated values of $\lambda_{r}, i_{s d}$, and $i_{s q}$ and the designated value of $\theta_{f}$ are used to generate reference voltages $\left(v_{s q}^{*}\right.$ and $\left.v_{s d}^{*}\right)$ from $d q$-axis currents $\left(i_{s d}^{*}\right.$ and $\left.i_{s q}^{*}\right)$ for SVPWM. The reference values of $v_{a}^{*}, v_{b}^{*}$, and $v_{c}^{*}$ for the three phase voltages are measured using $\theta_{f}$. The power electronics converter is based on SVPWM switching technique to deliver real stator voltages $v_{a}, v_{b}$, and $v_{\mathcal{c}}[25]$.

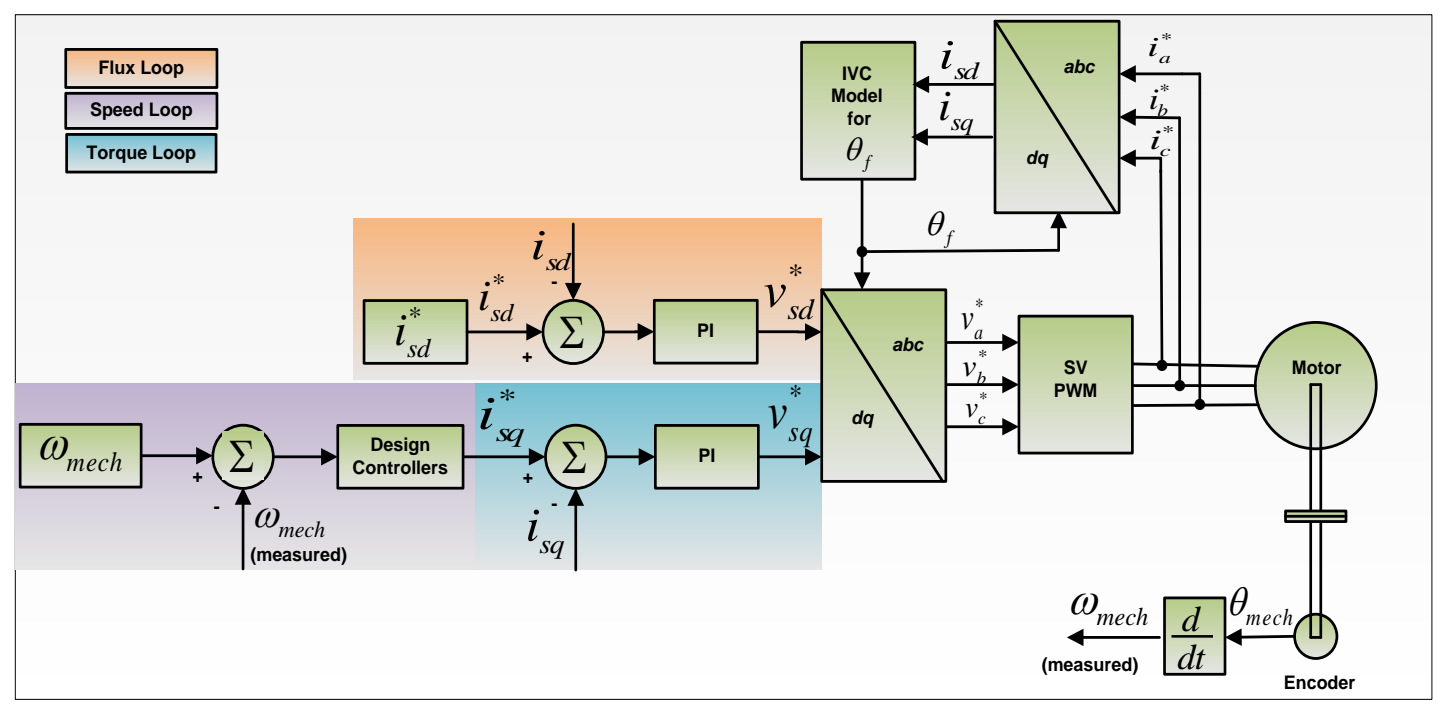

Figure 5. Proposed model of the Indirect Field Oriented Control (IFOC).

The SVPWM is designed from [24,25]. In the case of Sinusoidal Pulse Width Modulation (PWM) $V_{L L, \max }(r m s)=0.612 V_{d}$ and SVPWM $V_{L L, \max }(r m s)=0.707 V_{d}$. The SVPWM utilizes $15 \%$ higher DC-bus voltage. The reference current $i_{s q}^{*}$ is used to control the IM torque. The control structure is 
composed of two cascaded loops. The inner loop is used to control the torque while the outer loop is used to control the speed of the IM. The bandwidth of the inner loop is larger than the outer loop. The advance adaptive and robust controllers are used to minimize the error between the reference value and measured value and provide a reference current $i_{s q}^{*}$ to the internal loop. The PI controller is used to minimize the error of the $q$-axis current $i_{s q}$. Similarly, the error of the $d$-axis current $i_{s d}$ is also controlled by using a conventional PI controller [24].

\section{Optimal Speed Controllers: A Design Overview}

This section briefly describes the design and overview of different proposed controllers for indirect FOCS IM.

\subsection{PI Control Scheme Design}

The baseline PI controller is comprehensively designed and tuned in [24]. The PI controller constants for the speed loop are calculated on the basis that the phase margin is $60^{\circ}$ and the crossover open loop frequency is $25 \mathrm{rad} / \mathrm{s}$. However, the torque loop has the same phase margin with 10 times the bandwidth of the speed loop.

\subsection{Adaptive PI Control Scheme Design}

The PI controller has constant proportional and integral gains: $k_{p}$ and $k_{i}$, respectively. The performance of the PI control scheme is enhanced by updating the gains, according to error $e(t)$. The adaptation is achieved by employing Fuzzy Rules (FR). FR are simple If-THEN rules (or algorithms) with a condition and conclusion. FR are constructed to control the output variables as follows:

- If the absolute error $|e(t)|$ is zero, then $k_{p}$ is large and $k_{i}$ is zero.

- If the absolute error $|e(t)|$ is small, then $k_{p}$ is large and $k_{i}$ is small.

- If the absolute error $|e(t)|$ is large, then $k_{p}$ is large and $k_{i}$ is large.

In fuzzification and de-fuzzification the membership functions are required to convert crisp input into fuzzified output and vice versa. A Gaussian Membership Function (GMF) is employed in the fuzzy rules that utilizes two update parameters, i.e., standard deviation or variance $\sigma_{i}$ and center $c_{i}$ as:

$$
\mu(x)=\exp \left(-\frac{1}{2}\left(\frac{x_{i}-c_{i}}{\sigma_{i}}\right)^{2}\right)
$$

Mathematically, a PI controller is described as:

$$
i_{s q}^{*}(P I)=k_{p} e(t)+k_{i} \int e(t) d t
$$

where the controller input is $e(t)$, output of the controller is $i_{s q}^{*}$, and $k_{p}$ and $k_{i}$ are proportional and integral gains, respectively. Figure 6 demonstrates the adaptive fuzzy PI control scheme for the IFOC IM drive system. The error is minimized by updating PI gains using fuzzy rules. The update equation for the designed controller is presented in Equation (14).

$$
i_{s q}^{*}(F u z z y)=F_{1} K_{1} e(t)+F_{2} K_{2} \int e(t) d t
$$

where $F_{1}$ and $F_{2}$ are the output of the fuzzy controller for $k_{p}$ and $k_{i}$ and $K_{1}$ and $K_{2}$ are learning rate constants for $k_{p}$ and $k_{i}$, respectively. 


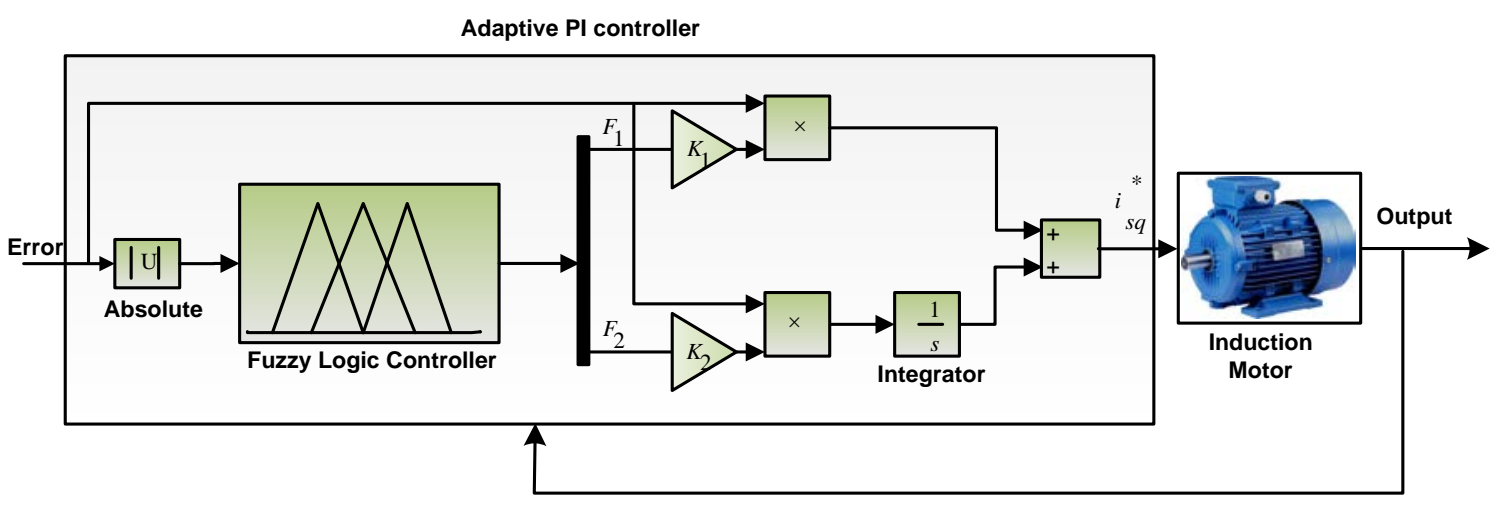

Figure 6. Adaptive Proportional Integral (PI) controller [25].

\subsection{Proposed FLC based on $L M$}

This segment describes the design of proposed FLC based on an LM algorithm. In the literature, different control schemes are implemented for IFOC IM drives, each approach has its own favorable characteristics [26]. FLC based on LM is the most appropriate for the non-linear, inadequately understood, and complex dynamic plants. FLC based on LM does not require an exact mathematical model and is known as a direct adaptive control procedure. IM can be optimally controlled by FLC based on the LM technique [27]. The knowledge base modifier handles the uncertainty of a non-linear model, while the updating of the singleton Membership Function (MF) makes the controller adaptive.

The selection of LM technique is based on the following discussion. Because of smaller step sizes, FLC based on SD is always convergent. The SD algorithm is slow but convergent $[27,28]$. The probability of divergence increases in the Gauss-Newton (GN) procedure, although it minimizes the error function faster than does the SD technique. At any time, if the Jacobian matrix inverse inclines to infinity, the GN procedure fails. The LM technique is a hybrid method which is stable with the Jacobian matrix, uses the fastness of GN, and the convergence property of SD [27]. LM technique optimally solves least square minimization problems. The cost function of a control scheme is optimized by the LM algorithm as $[25,28]$ :

$$
f(x)=\frac{1}{2} \sum_{j=1}^{m} r_{i}^{2}(x)
$$

In Equation (15), $x=\left[\begin{array}{lllll}x_{1} & x_{2} & x_{3} & \cdots & x_{n}\end{array}\right]^{T} \in R^{n \times 1}$ and $r_{i}$ is the function from $R^{n}$ to $R$. It is assumed that $m \geq n$ for the $r_{i}$, where $r_{i}$ is called the residuals. The different parameters of the LM algorithm is updated by the following equation.

$$
w_{k+1}=w_{k}-\lambda\left(J_{k}^{T} J_{k}+\mu I\right)^{-1} J_{k} e_{k}
$$

$w_{k+1}$ presents the updated value, $J_{k}$ is the Jacobean matrix, $w_{k}$ is the previous value, $\mu$ is the combination coefficient, $I$ is the identity matrix, and $e_{k}$ is the error. In order to guarantee that the estimated Hessian Matrix (HM) is convertible, the LM technique familiarizes another approximation to HM as:

$$
H \cong\left(J_{k}^{T} J_{k}+\mu I\right)^{-1}
$$

The parameters $\mu$ and $\lambda$ are used to make the algorithm stable and convergent [26]. Furthermore, FLC integrates four individual parts: fuzzifier that converts crisp input into fuzzy output using a membership function, simple rule base of IF-THEN rules or algorithms that are fired to control output, inference engine that evaluates the rules and dictates which rules should be fired, and de-fuzzifier that converts the inference conclusion into crisp or real output as presented in Figure 7. 


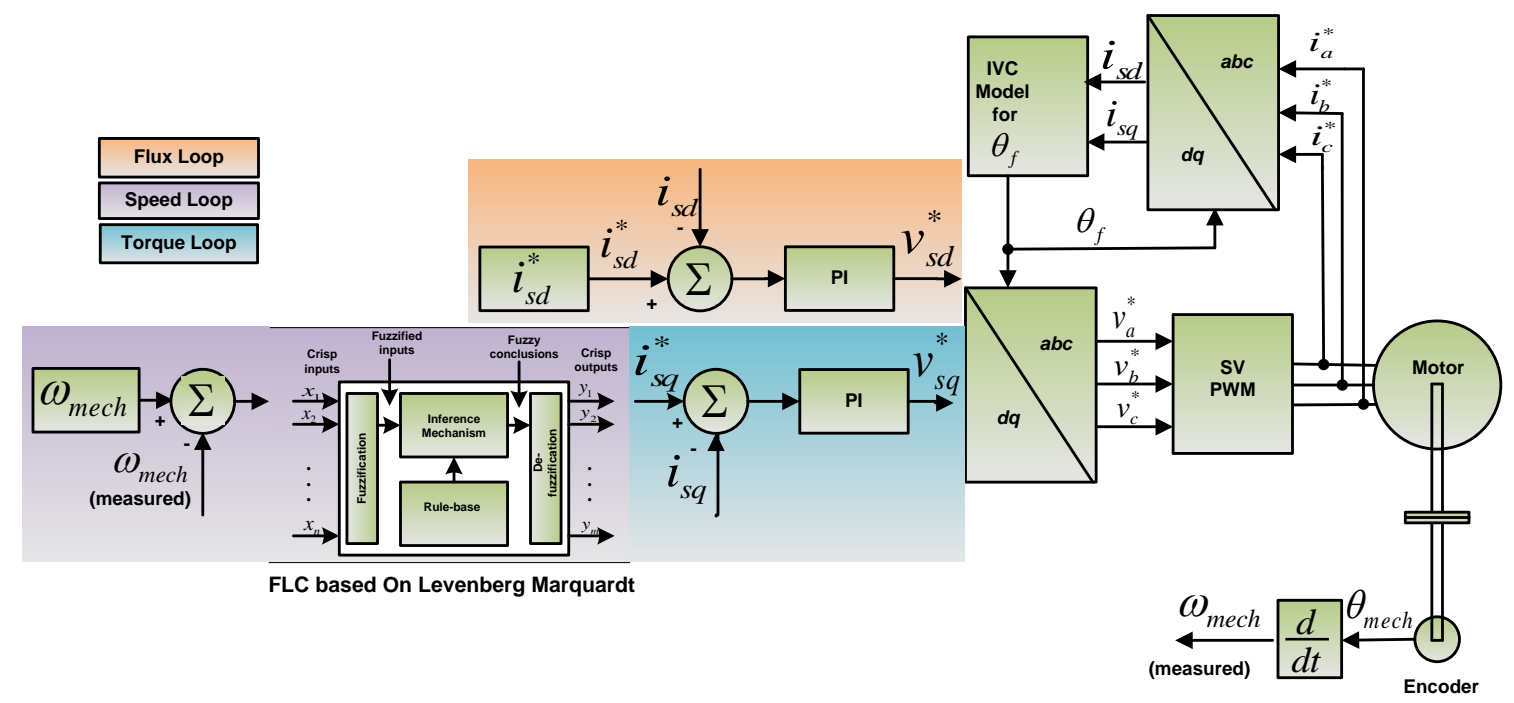

Figure 7. Fuzzy Logic Control (FLC) based on the Levenberg-Marquardt (LM) algorithm.

\subsubsection{Controller Output Equation}

The design develops from the Cost equation as:

$$
e_{m}=\frac{1}{2}\left[f_{m}-y_{r e f}\right]^{2}
$$

The center of gravity approach is utilized to accomplish the de-fuzzification of output MF as described in the accompanying Equation.

$$
f_{m}=\frac{\left(\sum_{i=1}^{R} b_{i} \mu_{i}\left(x_{j}^{m}, k\right)\right)}{\left(\sum_{i=1}^{R} \mu_{i}\left(x_{j}^{m}, k\right)\right)}
$$

Equation (18), the FLC based on LM output, and input MFs are updated according to output MFs, as presented in Equation (18).

The updating of the Gaussian Membership Function (GMF) is faster and works well for continuous functions, additionally, it update two parameters i.e., Center $c_{i}$ and Variance $\sigma_{1}$.

\subsubsection{Jacobian Calculation}

Derivative of cost Equation (17), w.r.t output MF $b_{j}$ is:

$$
\frac{\partial e_{m}}{\partial b_{i}}=\left(f_{m}-y_{r e f}\right) \frac{\partial \varepsilon}{\partial b_{i}}
$$

By substituting the estimations of GMF we obtain:

$$
\begin{gathered}
\frac{\partial e_{m}}{\partial b_{i}}=\varepsilon \frac{\partial}{\partial b_{i}}\left[\frac{\left(\sum_{i=1}^{R} b_{i} \mu_{i}\left(x_{j}^{m}, k\right)\right)}{\left(\sum_{i=1}^{R} \mu_{i}\left(x_{j}^{m}, k\right)\right)}\right] \\
\frac{\partial e_{m}}{\partial b_{i}}=\varepsilon \frac{\partial}{\partial b_{i}}\left[\frac{\left(\sum_{i=1}^{R} b_{i} \prod \exp \left(-\frac{1}{2}\left(\frac{x_{j}^{m}-c_{j}^{i}}{\sigma_{j}^{i}}\right)^{2}\right)\right)}{\left(\sum_{i=1}^{R} \prod \exp \left(-\frac{1}{2}\left(\frac{x_{j}^{m}-c_{j}^{i}}{\sigma_{j}^{i}}\right)^{2}\right)\right)}\right]
\end{gathered}
$$


The Jacobian of each span, i.e., output MF, variance, and center, is obtained by derivating the cost equation. The Jacobian of output GMF $b_{i}$ is given in Equations (19)-(21). Similarly, by derivating the cost equation w.r.t. $c_{i}$ and $\sigma_{i}$, we individually demonstrate the Jacobian of the center and variance of the GMF.

\subsubsection{Update Equation for Output Membership Function}

The output of the controller or the output MF is updated by Equation (22). The output MF is presented by variable $b_{i}$. The output of the controller is updated regularly according to the output to minimize the error.

$$
b_{i}(k)=b_{i}(k-1)-\lambda\left[\left[\varepsilon\left[\frac{\mu_{i}\left(x_{j}^{m}, k\right)}{\sum_{i=1}^{R} \mu_{i}\left(x_{j}^{m}, k\right)}\right]\right]\left[\left[\varepsilon\left[\frac{\mu_{i}\left(x_{j}^{m}, k\right)}{\sum_{i=1}^{R} \mu_{i}\left(x_{j}^{m}, k\right)}\right]\right]\right]^{T}+\mu I\right]^{-1}\left[\varepsilon\left[\frac{\mu_{i}\left(x_{j}^{m}, k\right)}{\sum_{i=1}^{R} \mu_{i}\left(x_{j}^{m}, k\right)}\right]\right] \varepsilon
$$

\subsubsection{Update Equation for Variance}

Equation (23) demonstrates the adaptation of variance $\sigma_{i}$ or the spread of the MF. There is an inverse relation between variance and the magnitude of MF. The notch will be greater if the variance value is lower, and vice versa.

$$
\sigma_{i}(k)=\sigma_{i}(k-1)-\lambda\left[A A^{T}+\mu I\right]^{-1} A \varepsilon
$$

where $A=\left[\varepsilon\left[\frac{\left(\sum_{i=1}^{R} b_{i}\right)-f_{m}}{\sum_{i=1}^{R} \mu_{i}\left(x_{j}^{m}, k\right)}\right]\left(\frac{\left(x_{j}^{m}-c_{j}^{i}\right)^{2}}{\left(\sigma_{j}^{i}\right)^{3}}\right) \mu_{i}\left(x_{j}^{m}, k\right)\right]$.

\subsubsection{Update Equation for Center}

Based on the crisp input to the controller, the GMF center acquires different values, which are given by Equation (24).

$$
c_{i}(k)=c_{i}(k-1)-\lambda\left[B B^{T}+\mu I\right]^{-1} B \varepsilon
$$

where $B=\left[\varepsilon\left[\frac{\left(\sum_{i=1}^{R} b_{i}\right)-f_{m}}{\sum_{i=1}^{R} \mu_{i}\left(x_{j}^{m}, k\right)}\right]\left(\frac{\left(x_{j}^{m}-c_{j}^{i}\right)}{\left(\sigma_{j}^{i}\right)^{2}}\right) \mu_{i}\left(x_{j}^{m}, k\right)\right]$.

\subsection{Proposed Fuzzy Logic Controller Based on SD}

The Steepest Descent (SD) algorithm is also known as the Error Back-Propagation (EBP) or first order-order algorithm as it employs a first derivative to reduce error. The updated equation of FLC based on SD is given as:

$$
w_{k+1}=w_{k}-\alpha g_{k}
$$

where $g_{k}$ is the gradient while $\alpha$ is the step size or learning rate constant. According to the EBP update rule, as illustrated in Figure 8, the equation that updates the center, variance, and output membership function are similar to the FLC based on LM with little modification. The asymptotic convergence principle is followed by the FLC based on SD technique for a training process. Around the solution, all the elements of the gradient vector will be very trivial. In addition, in comparison to the LM and GN techniques, the weight change is small.

\subsubsection{Update Equation for Output Membership Function}

The derivative of the learning error function equation with respect to output MF $b_{j}$ results in the calculation of a gradient through the following subsequent equations: 


$$
\frac{\partial e_{m}}{\partial b_{i}}=\left(f_{m}-y_{r e f}\right) \frac{\partial \varepsilon}{\partial b_{i}}
$$

By placing the estimations of GMF we get:

$$
\begin{gathered}
\frac{\partial e_{m}}{\partial b_{i}}=\varepsilon \frac{\partial}{\partial b_{i}}\left[\frac{\left(\sum_{i=1}^{R} b_{i} \mu_{i}\left(x_{j}^{m}, k\right)\right)}{\left(\sum_{i=1}^{R} \mu_{i}\left(x_{j}^{m}, k\right)\right)}\right] \\
\frac{\partial e_{m}}{\partial b_{i}}=\varepsilon \frac{\partial}{\partial b_{i}}\left[\frac{\left(\sum_{i=1}^{R} b_{i} \prod \exp \left(-\frac{1}{2}\left(\frac{x_{j}^{m}-c_{j}^{i}}{\sigma_{j}^{i}}\right)^{2}\right)\right)}{\left(\sum_{i=1}^{R} \Pi \exp \left(-\frac{1}{2}\left(\frac{x_{j}^{m}-c_{j}^{i}}{\sigma_{j}^{i}}\right)^{2}\right)\right)}\right]
\end{gathered}
$$

The finalized law for updated output MF is given as:

$$
b_{i}(k)=b_{i}(k-1)-\alpha \frac{\partial}{\partial b_{i}}\left[\frac{\left(\sum_{i=1}^{R} b_{i} \Pi \exp \left(-\frac{1}{2}\left(\frac{x_{j}^{m}-c_{j}^{i}}{\sigma_{j}^{i}}\right)^{2}\right)\right)}{\left(\sum_{i=1}^{R} \Pi \exp \left(-\frac{1}{2}\left(\frac{x_{j}^{m}-c_{j}^{i}}{\sigma_{j}^{i}}\right)^{2}\right)\right)}\right] \varepsilon
$$

\subsubsection{Update Equation for Variance}

The update law for variance is obtained by taking the derivative of Equation (25b) w. r. t. $\sigma_{i}(k)$ and putting the final values in Equation (25a) as presented in Equation (25f).

$$
\sigma_{i}(k)=\sigma_{i}(k-1)-\alpha\left[\varepsilon\left[\frac{\left(\sum_{i=1}^{R} b_{i}\right)-f_{m}}{\sum_{i=1}^{R} \mu_{i}\left(x_{j}^{m}, k\right)}\right]\left(\frac{\left(x_{j}^{m}-c_{j}^{i}\right)^{2}}{\left(\sigma_{j}^{i}\right)^{3}}\right) \mu_{i}\left(x_{j}^{m}, k\right)\right] \varepsilon
$$

\subsubsection{Update Equation for Center}

Similarly, the update relation for the center is acquired:

$$
c_{i}(k)=c_{i}(k-1)-\alpha\left[\varepsilon\left[\frac{\left(\sum_{i=1}^{R} b_{i}\right)-f_{m}}{\sum_{i=1}^{R} \mu_{i}\left(x_{j}^{m}, k\right)}\right]\left(\frac{\left(x_{j}^{m}-c_{j}^{i}\right)}{\left(\sigma_{j}^{i}\right)^{2}}\right) \mu_{i}\left(x_{j}^{m}, k\right)\right] \varepsilon
$$

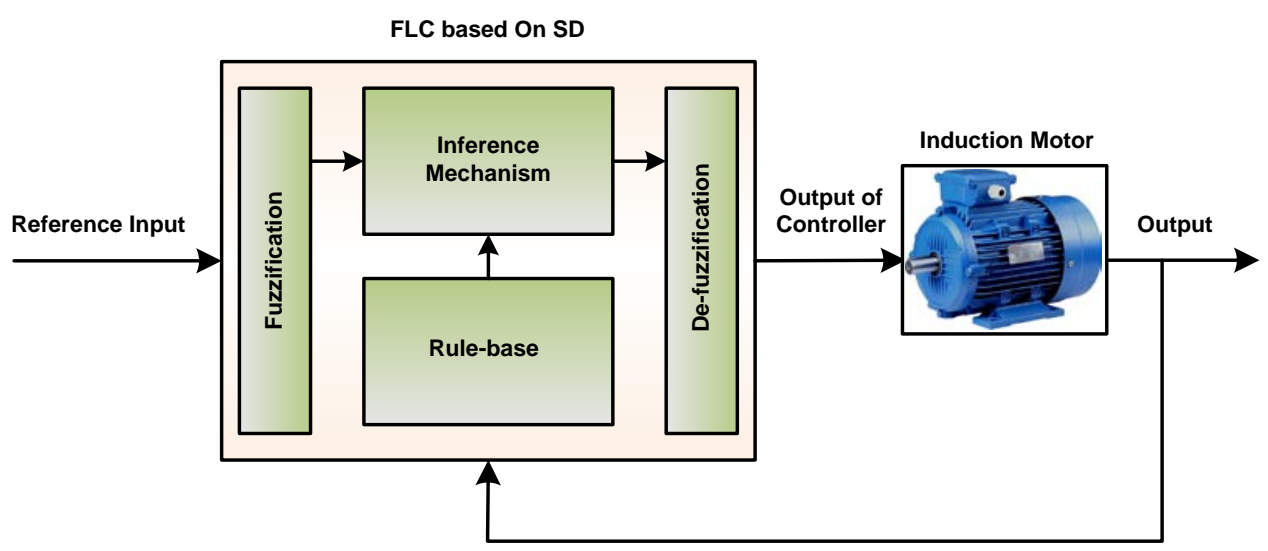

Figure 8. FLC based on the Steepest Descent (SD). 
Figure 8 shows a block diagram of the FLC based on the SD technique. The implementation of the proposed scheme is carried out in a closed-loop control system. The FLC based on the SD algorithm performs fuzzification of input, selects a specific rule from the set of rules, and finally de-fuzzifies the error function to generate a control signal to the plant.

\subsection{Sliding Mode Control (SMC) Strategy}

The SMC is a non-linear control scheme applicable to linear and non-linear systems. SMC has the remarkable features of robustness, accuracy, easy implementation, and tranquil tuning. SMC is insensitive to disturbance rejection and parameter variation $[12,13,29,30]$. The mechanical equation of the IM is represented as:

$$
T_{e}=J \dot{\omega}_{m}+B \omega_{m}+T_{L}
$$

The mechanical equation based on IFOC is equivalently described as:

$$
T_{e}=k_{T} i_{s q}
$$

where $k_{T}$ is electromagnetic torque constant and is represented as:

$$
k_{T}=\frac{3 P L_{m}}{4 L_{r}} \lambda_{r d}
$$

Substituting Equation (27a) into Equation (26), we have:

$$
b i_{q s}=\dot{\omega}_{m}+a \omega_{m}+f
$$

where $b=K_{T} / J, a=B / J$, and $f=T_{L} / J$. Applying uncertainties $\Delta a, \Delta b$, and $\Delta f$ in terms of $a, b$, and $f$, respectively, we have:

$$
\omega_{m}=(b+\Delta b) i_{s q}-(a+\Delta a) \omega_{m}-(f+\Delta f)
$$

The error equation for speed is defined as:

$$
e(t)=\omega_{m}(t)-\omega_{m}^{*}(t)
$$

where $\omega_{m}^{*}$ is the reference rotor speed. Derivating Equation (27c), with respect to time provides:

$$
\begin{gathered}
\dot{e}(t)=\dot{\omega}_{m}(t)-\dot{\omega}_{m}^{*}(t)=-a e(t)+u(t)+d(t) \\
u(t)=b i_{s q}-a \omega_{m}^{*}(t)-f(t)-\dot{\omega}_{m}^{*}
\end{gathered}
$$

and the uncertainties $d(t)$ are: $d(t)=\Delta b i_{s q}-\Delta a \omega_{m}-\Delta f$.

The Sliding Surface (SS) $S(t)$ with an integral component for the speed loop is defined as:

$$
S(t)=e(t)-\int_{0}^{t}(k-a) e(\tau) d \tau
$$

The SMC controller is designed to drive the error to the sliding surface as presented in Figure 9. At the SS error, the derivative and integral of error tend to zero. In SMC the designed control system trajectories are forced towards SS. The SMC consists of SS and control law designing. Moreover, the discontinuous control law results in chattering in the system that is overcome by adapting continuous control law, where $k$ is the constant defining the slope of SS, and is equal to $k<0$. $S(t)=\dot{S}(t)=0$ at SS. The controlled system dynamic behaviour is represented as:

$$
\dot{e}(t)-(k-a) e(t)=0
$$




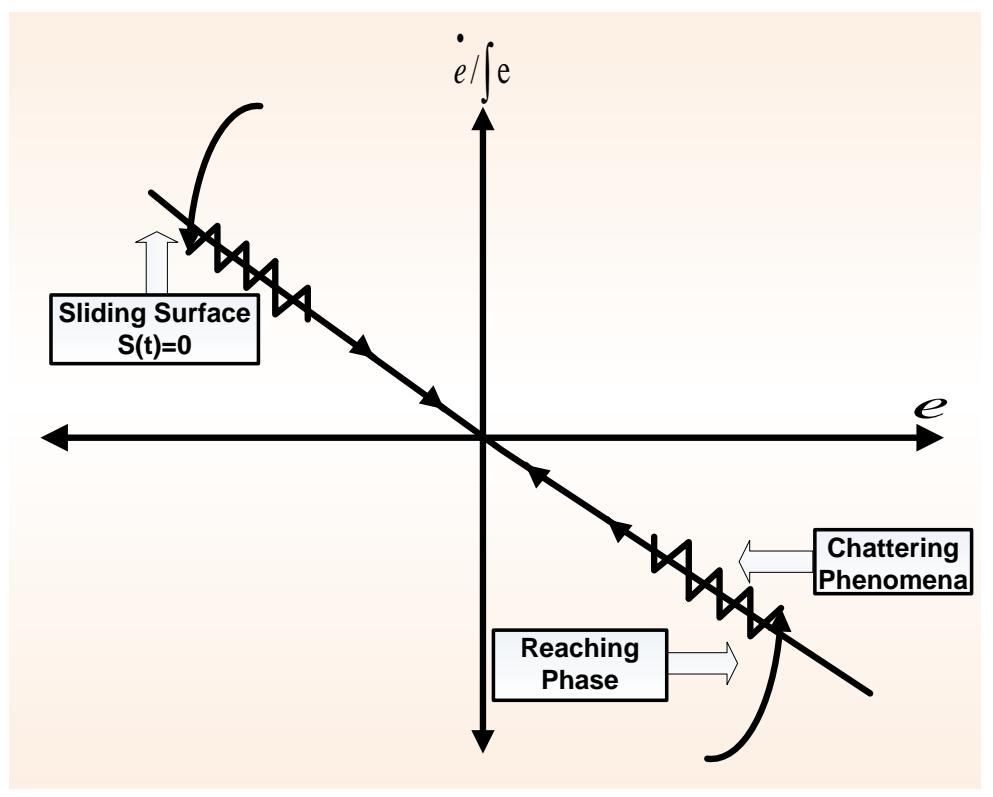

Figure 9. Graphical interpretation of the sliding mode controller.

The variable structure controller is designed as:

$$
u(t)=k e(t)-\beta \operatorname{sgn}(S)
$$

In Equation (28c), $\beta$ is the switching gain and is constrained to $\beta \geq|d(t)| . S$ is the SS and $\operatorname{sgn}($. is the sign function and is represented as:

$$
\operatorname{Sgn}(S(t))=\left\{\begin{aligned}
1 & \text { if } S(t)>0 \\
-1 & \text { if } S(t)<0
\end{aligned}\right.
$$

Substituting Equation (28c) into Equation (28a), $i_{s q}^{*}$ command is obtained as:

$$
i_{s q}^{*}=\frac{1}{b}\left[k e-\beta \operatorname{sgn}(s)+a \omega_{m}^{*}(t)+\dot{\omega}_{m}^{*}(t)+f\right]
$$

\subsection{Designed Hybrid Controller}

The proposed HC or Fuzzy Sliding Mode Controller incorporates two adaptive non-linear control techniques: (a) Sliding Mode Control (SMC) and (b) PI-fuzzy control. The advantageous features of the SMC and PI-fuzzy control are combined in HC [31]. The SMC minimizes error in transient states, enlarging a system's stability and providing a fast-dynamic response. Chattering is reduced by PI-fuzzy during steady state. Figure 10 demonstrates the designed HC scheme. The $k_{p}$, and $k_{i}$ values are updated using a sliding surface based on fuzzy rules. The SS control law is designed for the updated values from the fuzzy-PI control scheme. The HC aim is to design a control law that tracks reference speed [32]. Error and derivative of error are always directed towards the sliding surface in SMC. SS $S(t)$ with a derivative component of the speed loop is defined as:

$$
S(t)=\dot{e}(t)+\lambda e(t)
$$

In Equation (30a), $\lambda$ is a positive arbitrary constant that is bandwidth dependent of the system and is defined as:

$$
\lambda e(t)=F_{1} K_{1} e(t)+F_{2} K_{2} \int e(t) d t
$$


The $\lambda e(t)$ is updated using the adaptive PI controller. The discontinuous control law introduced in Equation (31a) causes oscillations in the electrical system where PWM control signals are employed.

$$
i_{s q}^{*}=-U \operatorname{sgn}(S)
$$

where $U$ is a sufficiently large positive constant and

$$
\operatorname{Sgn}(S(t))=\left\{\begin{aligned}
U & \text { if } S>0 \\
-U & \text { if } S<0
\end{aligned}\right.
$$

To minimize the chattering phenomena, the alternate control law is used to implement a continuous smooth approximation instead of the discontinuous "sgn" function described as:

$$
i_{s q}^{*}=-U s a t(\sigma ; \varepsilon)=\left[-U \frac{S}{|S|+\varepsilon}\right] \quad \varepsilon>0 \quad \varepsilon \approx 0
$$

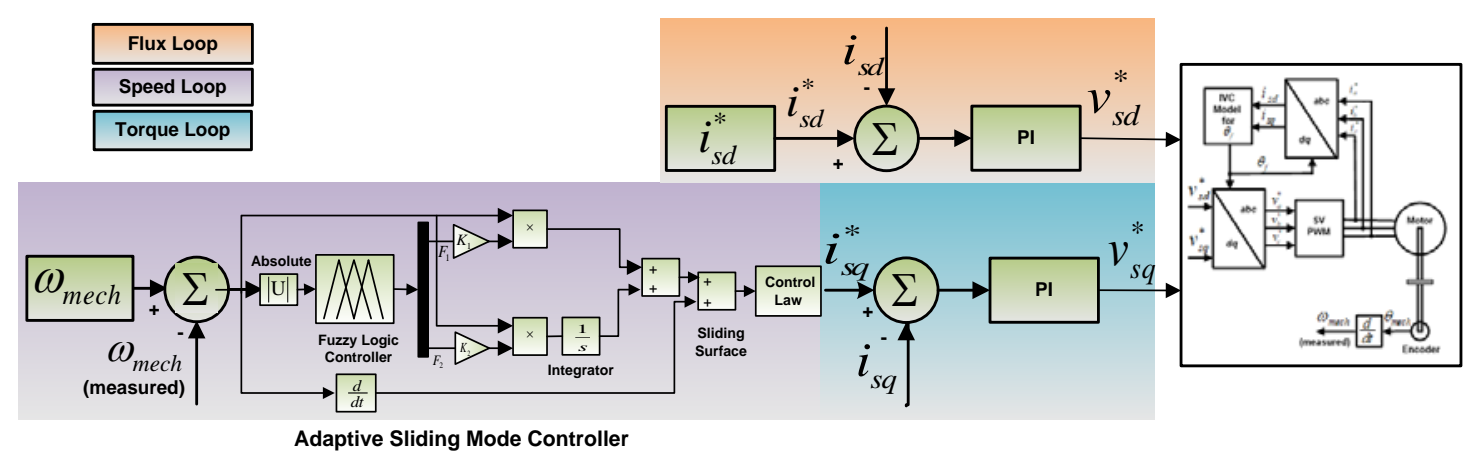

Figure 10. Hybrid controller design.

\section{Results and Discussions}

The performance of the designed control strategies, for example, PI, adaptive PI, FLC based on LM, fuzzy logic (FL) based on SD, SMC, and HC was validated and investigated by several simulation results. For the IFOC IM drive system, the software used for results was MATLAB/Simulink (R2017a, MathWorks, Natick, MA, USA). The designed system was subjected to different perturbations, namely: parameter uncertainties, speed variation, electrical faults, and load disturbances. Initially, the drive was started from a halt condition; by sustaining the torque at zero, the rated flux was attained. The fundamental purpose of the simulations was twofold. First, to authenticate the exceptional robustness and outcomes of the designed control strategies. Second, to relate the effectiveness of the proposed control approaches. Table A1 summarizes the parameters of the IM, furthermore, the update constants used by the designed control schemes are elaborated in Table A2.

\subsection{Rotor Resistance and Load Disturbances}

The disturbance rejection capability for the proposed control schemes was verified by applying a full load till $t=1 \mathrm{~s}$, and for the rest of the test the load was halved. Moreover, to verify the robustness of the design control strategies for parameter uncertainty, $R_{r}$ was varied from rated to $120 \%, 150 \%$, and $200 \%$ of the rated values. As illustrated in Figure 11 at rated $R_{r}$, the PI controller simulation results confirm slow convergence, high transient oscillation, and SSE for parameter and load variation. The performance evaluation of the proposed optimal control schemes is elaborated in Table 1. The result of the adaptive PI control scheme is demonstrated in Figure 12. The proposed control scheme validates less susceptibility to parameter uncertainty and sudden load disturbances, with a small SSE and approximately negligible oscillation. 


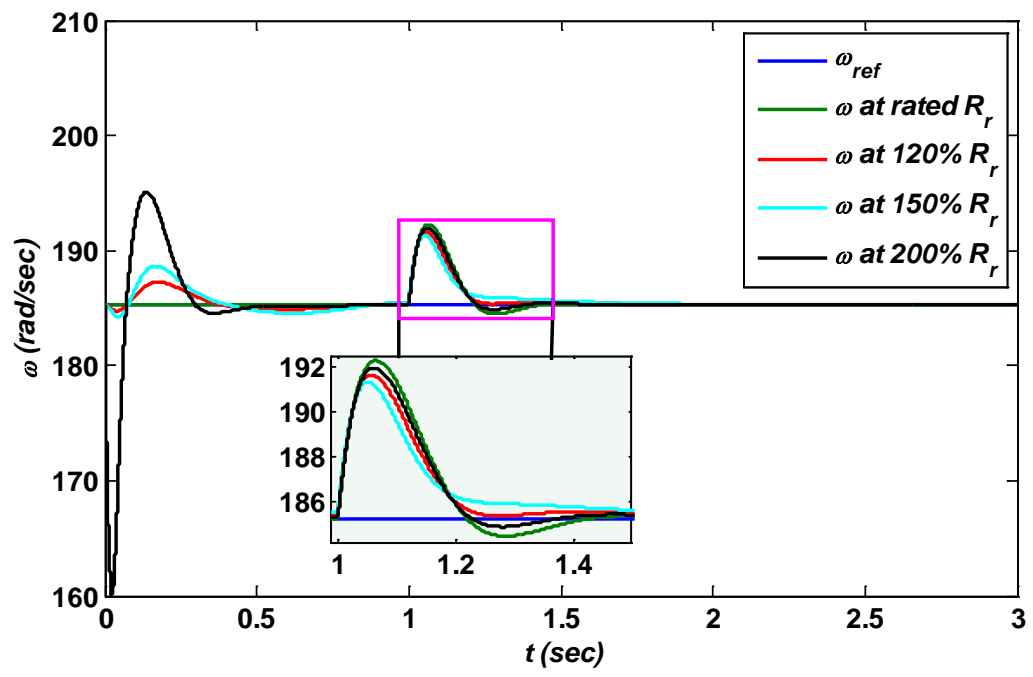

Figure 11. Speed control of indirect field oriented control IM using a PI controller.

Table 1. Performance assessment of designed controllers.

\begin{tabular}{cccccccc}
\hline Control Strategies & OS & US & RT & FT & IAE & ISE & ITAE \\
\hline & $(1) .6 .746$ & $(1) .0 .754$ & $(1) .37 .82$ & $(1) .103 .8$ & $(1) .0 .997$ & $(1) .4 .792$ & $(1) .1 .114$ \\
PI & $(2) .6 .770$ & $(2) .0 .753$ & $(2) .31 .88$ & $(2) .14 .11$ & $(2) .3 .295$ & $(2) .32 .96$ & $(2) .1 .312$ \\
& $(3) .6 .781$ & $(3) .0 .454$ & $(3) .33 .59$ & $(3) .120 .4$ & $(3) .1 .425$ & $(3) .4 .318$ & $(3) .1 .232$ \\
& $(4) .10 .14$ & $(4) .25 .25$ & $(4) .35 .27$ & $(4) .279 .0$ & $(4) .1 .864$ & $(4) .4 .858$ & $(4) .1 .515$ \\
\hline \multirow{5}{*}{ Adaptive PI } & $(1) .1 .106$ & $(1) .1 .554$ & $(1) .373 .3$ & $(1) .2 .760$ & $(1) .0 .315$ & $(1) .0 .170$ & $(1) .0 .147$ \\
& $(2) .1 .103$ & $(2) .1 .654$ & $(2) .337 .1$ & $(2) .4 .044$ & $(2) .0 .286$ & $(2) .0 .151$ & $(2) .0 .146$ \\
& $(3) .1 .026$ & $(3) .1 .754$ & $(3) .181 .9$ & $(3) .3 .490$ & $(3) .0 .222$ & $(3) .0 .120$ & $(3) .0 .126$ \\
& $(4) .1 .186$ & $(4) .1 .854$ & $(4) .127 .8$ & $(4) .3 .405$ & $(4) .0 .223$ & $(4) .0 .118$ & $(4) .0 .144$ \\
\hline \multirow{5}{*}{ FL based on LM } & $(1) .0 .246$ & $(1) .0 .554$ & $(1) .265 .2$ & $(1) .2 .656$ & $(1) .0 .235$ & $(1) .0 .134$ & $(1) .0 .106$ \\
& $(2) .0 .346$ & $(2) .0 .204$ & $(2) .11 .38$ & $(2) .4 .238$ & $(2) .0 .298$ & $(2) .1 .352$ & $(2) .0 .102$ \\
& $(3) .0 .345$ & $(3) .0 .203$ & $(3) .181 .9$ & $(3) .3 .490$ & $(3) .0 .222$ & $(3) .0 .120$ & $(3) .0 .126$ \\
& $(4) .0 .376$ & $(4) .0 .199$ & $(4) .126 .6$ & $(4) .3 .731$ & $(4) .0 .296$ & $(4) .0 .197$ & $(4) .0 .200$ \\
\hline \multirow{5}{*}{ FL based on SD } & $(1) .0 .666$ & $(1) .0 .001$ & $(1) .2 .021$ & $(1) .6 .335$ & $(1) .0 .498$ & $(1) .0 .125$ & $(1) .0 .997$ \\
& $(2) .0 .665$ & $(2) .0 .079$ & $(2) .1 .933$ & $(2) .4 .060$ & $(2) .0 .559$ & $(2) .0 .150$ & $(2) .1 .104$ \\
& $(3) .0 .664$ & $(3) .0 .194$ & $(3) .1 .199$ & $(3) .243 .5$ & $(3) .0 .650$ & $(3) .0 .193$ & $(3) .1 .267$ \\
& $(4) .0 .663$ & $(4) .0 .424$ & $(4) .1 .623$ & $(4) .253 .5$ & $(4) .0 .784$ & $(4) .0 .257$ & $(4) .1 .470$ \\
\hline \multirow{5}{*}{ SM } & $(1) .0 .236$ & $(1) .0 .224$ & $(1) .812 .8$ & $(1) .0 .010$ & $(1) .0 .254$ & $(1) .0 .056$ & $(1) .0 .153$ \\
& $(2) .0 .237$ & $(2) .0 .301$ & $(2) .697 .8$ & $(2) .808 .0$ & $(2) .0 .209$ & $(2) .0 .021$ & $(2) .0 .220$ \\
& $(3) .0 .356$ & $(3) .0 .363$ & $(3) .609 .7$ & $(3) .0 .001$ & $(3) .0 .248$ & $(3) .0 .022$ & $(3) .0 .337$ \\
& $(4) .0 .376$ & $(4) .0 .365$ & $(4) .669 .4$ & $(4) .0 .001$ & $(4) .0 .290$ & $(4) .0 .030$ & $(4) .0 .471$ \\
\hline & $(1) .0 .036$ & $(1) .0 .014$ & $(1) .12 .08$ & $(1) .21 .19$ & $(1) .0 .010$ & $(1) .0001$ & $(1) .0 .007$ \\
& $(2) .0 .037$ & $(2) .0 .016$ & $(2) .0 .001$ & $(2) .168 .1$ & $(2) .0 .021$ & $(2) .0004$ & $(2) .0 .019$ \\
& $(2) .0 .038$ & $(3) .0 .017$ & $(3) .0 .006$ & $(3) .192 .9$ & $(3) .0 .010$ & $(3) .0005$ & $(3) .0 .008$ \\
& $(4) .0 .040$ & $(4) .0 .019$ & $(4) .0 .008$ & $(4) .143 .4$ & $(4) .0 .009$ & $(4) .0006$ & $(4) .0 .009$ \\
\hline
\end{tabular}

OS: Overshoot, US: Undershoot, RT: Rise Time, FT: Fall Time, ISE: Integral Square Error, SD: Steepest Descent, IAE: Integral Absolute Error, LM: Levenberg-Marquardt, ITAE: Integral of Time Weighted Absolute Error, FL: Fuzzy Logic, SM: Sliding Mode. Note: (1) Rated $R_{r}$, (2) $120 \%$ of rated $R_{r}$, (3) $150 \%$ of rated $R_{r}$, and (4) $200 \%$ of rated $R_{r}$.

The performance of the FLC based on LM is evaluated in Figure 13. The transient oscillation, settling time, and SSE increase comparatively less than with parameter and load variation. The FLC based on the SD technique SSE increases from $0.21 \mathrm{rad} / \mathrm{s}$ to $0.34 \mathrm{rad} / \mathrm{s}$ with parameter and load variation from rated $R_{r}$ to $200 \% R_{r}$ as illustrated in Figure 14. The convergence property of SMC is verified in Figure 15. The SSE is almost zero for rated $R_{r}$ and increases to $0.08 \mathrm{rad} / \mathrm{s}$ for $200 \%$ of rated 
$R_{r}$. Also, the behavior of SMC is oscillatory initially and settles after $t=1.5 \mathrm{~s}$. The HC strategy is investigated in Figure 16. The HC scheme results validate the insensitivity and robustness to parameter and load variation with fast settling time and zero SSE.

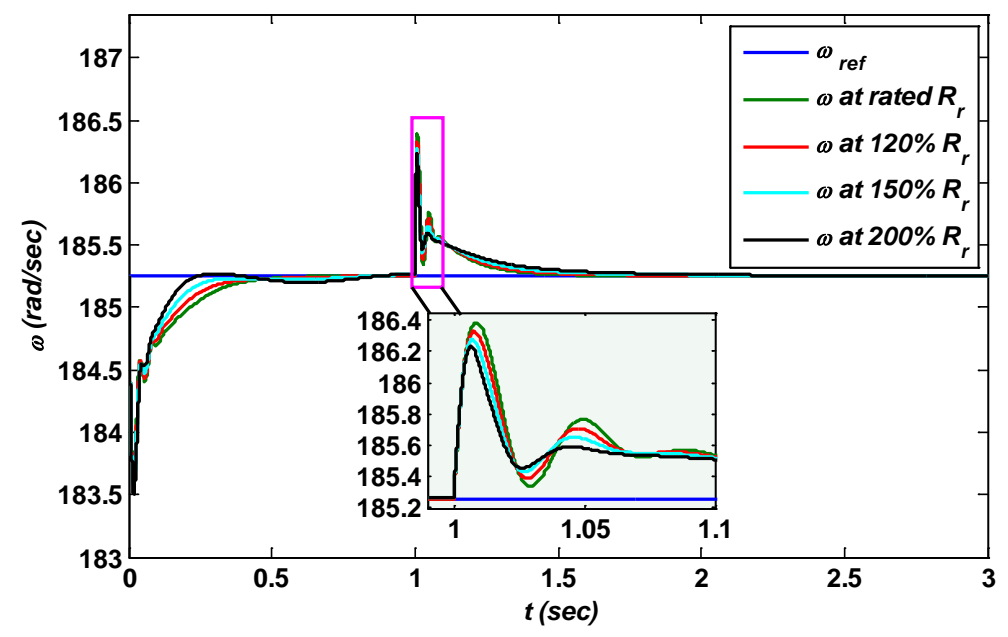

Figure 12. Speed control of indirect field oriented control IM using adaptive PI.

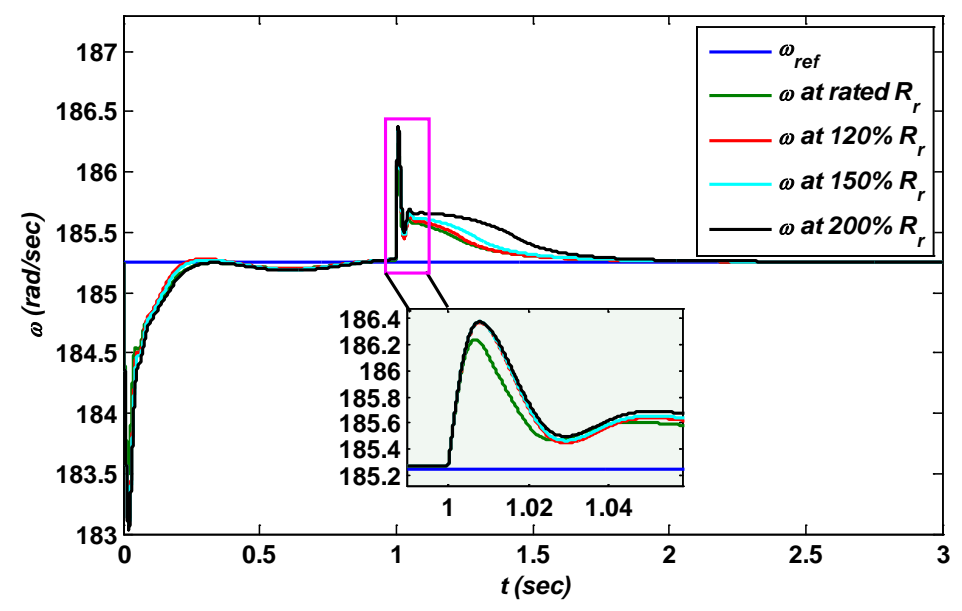

Figure 13. Speed control of IFOC IM using LM.

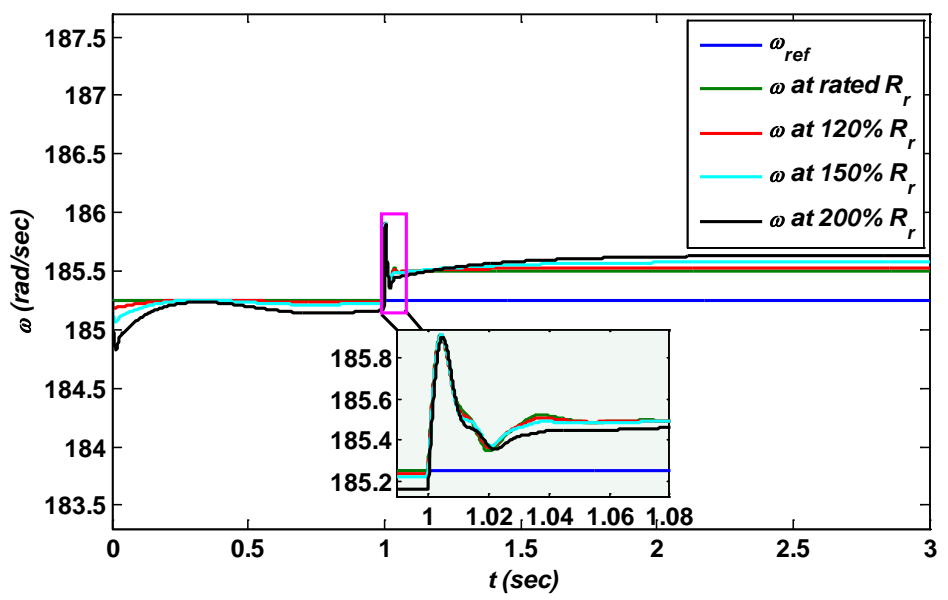

Figure 14. Speed control of IFOC IM using SD. 


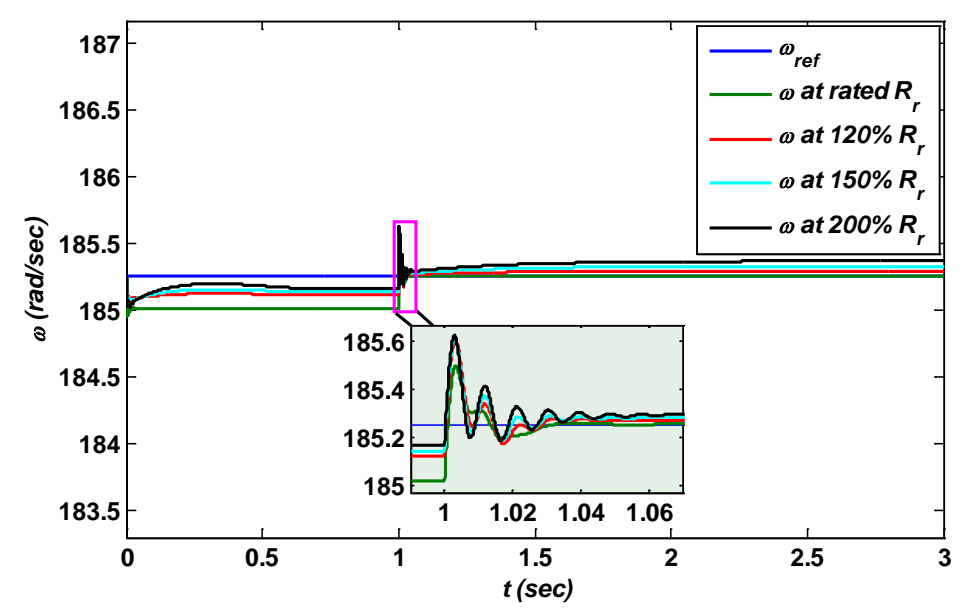

Figure 15. Speed control of IFOC IM using Sliding Mode Control (SMC).

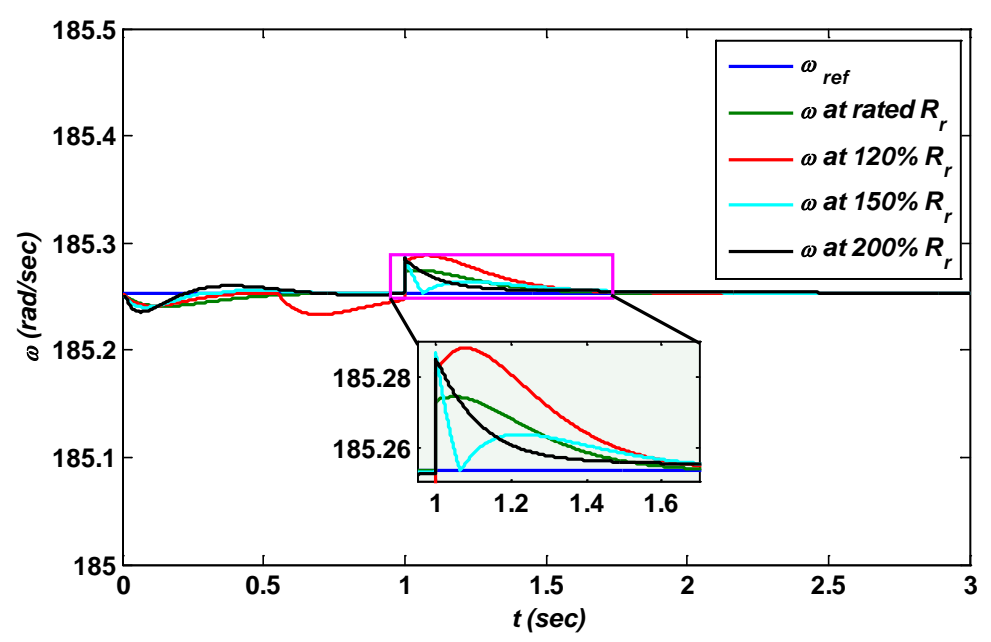

Figure 16. Speed control of IFOC IM using Hybrid Control (HC).

\subsection{Electrical Faults with Load Variation}

Electrical fault perturbation analysis evaluated stability and dynamic performance of the IFOC IM for the designed control strategies. The proposed system was subjected to various faults: (a) Single Phasing, (b) Double Phasing, (c) Under Voltage, and (d) Over Voltage, as demonstrated in Figures 17-20 respectively. In single phasing, phase "a" opened for $200 \mathrm{~ms}$ at $t=1 \mathrm{~s}$. Extra heat was generated in the stator winding because of more current being drawn by phase " $\mathrm{b}$ " and " $\mathrm{c}$ ". PI controller provided a large undershoot of $8.25 \mathrm{rad} / \mathrm{s}$ and overshoot of $14.25 \mathrm{rad} / \mathrm{s}$. Further, the PI control scheme settled after $t=1.8 \mathrm{~s}$, resulting a high oscillation in response. The responses of the adaptive PI, FLC based on LM, FLC based on SD, and SMC were almost the same with an average settling time of $t=1.3 \mathrm{~s}$, overshoot of $3.25 \mathrm{rad} / \mathrm{s}$, and undershoot of $3.75 \mathrm{rad} / \mathrm{s}$. The chattering phenomena in the SMC resulted in large oscillation. Moreover, HC strategies provided an undershoot of $0.05 \mathrm{rad} / \mathrm{s}$ and overshoot of $0.03 \mathrm{rad} / \mathrm{s}$ that settled at $t=1.3 \mathrm{~s}$ with negligible oscillation. The system was subjected to double phase fault at $t=1 \mathrm{~s}$ for $200 \mathrm{~ms}$ along with load variation. The undershoot of $28.25 \mathrm{rad} / \mathrm{s}$, overshoot of $72.75 \mathrm{rad} / \mathrm{s}$, settling time of $t=2 \mathrm{~s}$, and large dips were noted for the speed response by the PI control strategy. An average undershoot of $7.25 \mathrm{rad} / \mathrm{s}$, overshoot of $9.75 \mathrm{rad} / \mathrm{s}$, and settling time of $t=1.45 \mathrm{~s}$ along with chattering for adaptive PI, FLC based on LM, FLC based on SD, and SMC control schemes were found. Furthermore, an undershoot of $2.05 \mathrm{rad} / \mathrm{s}$, overshoot of $1.15 \mathrm{rad} / \mathrm{s}$, output settles after $t=1.5 \mathrm{~s}$, and negligible chattering was recorded for the HC scheme. 


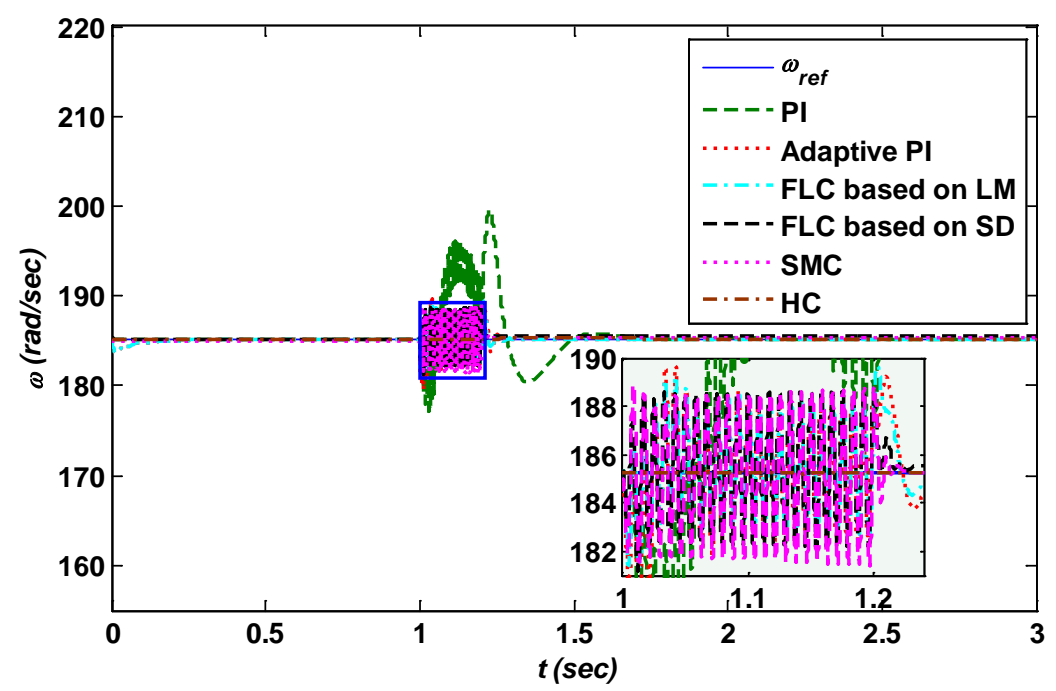

Figure 17. Single phasing.

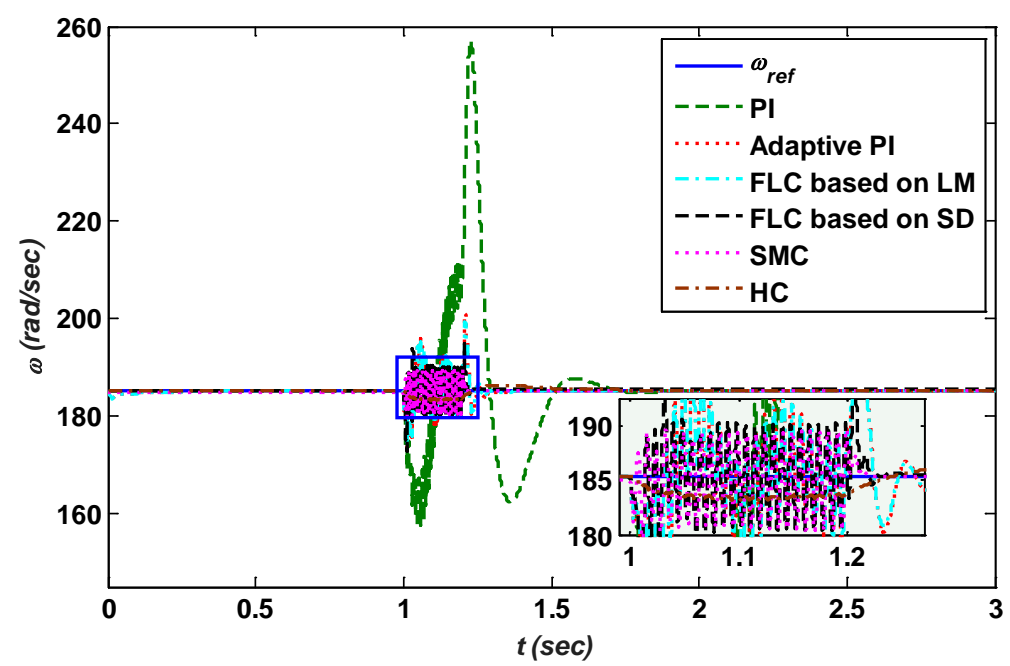

Figure 18. Double phasing.

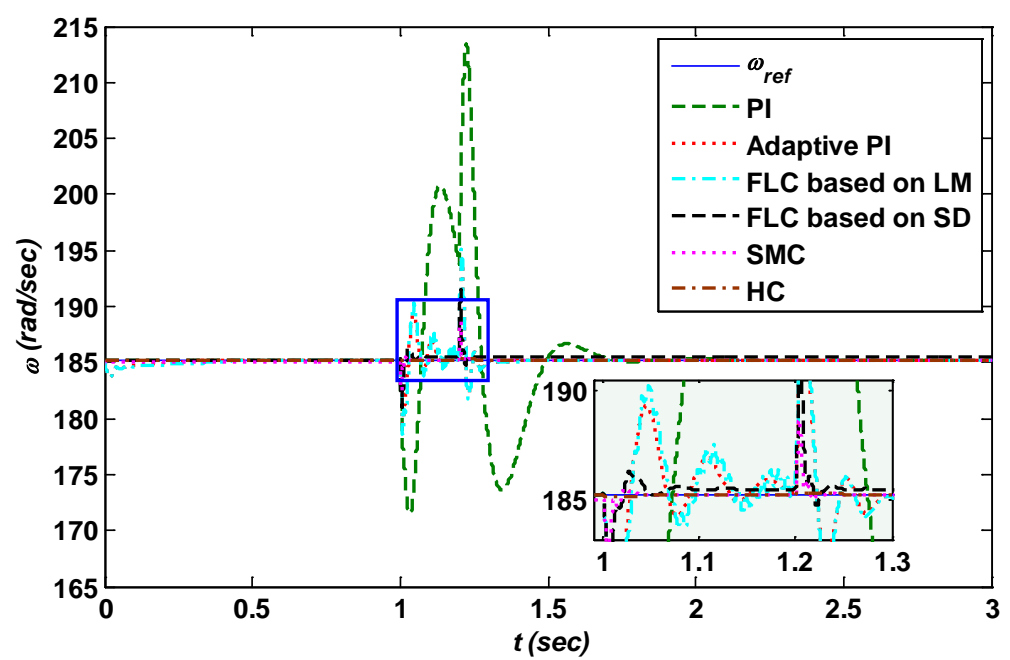

Figure 19. Undervoltage. 


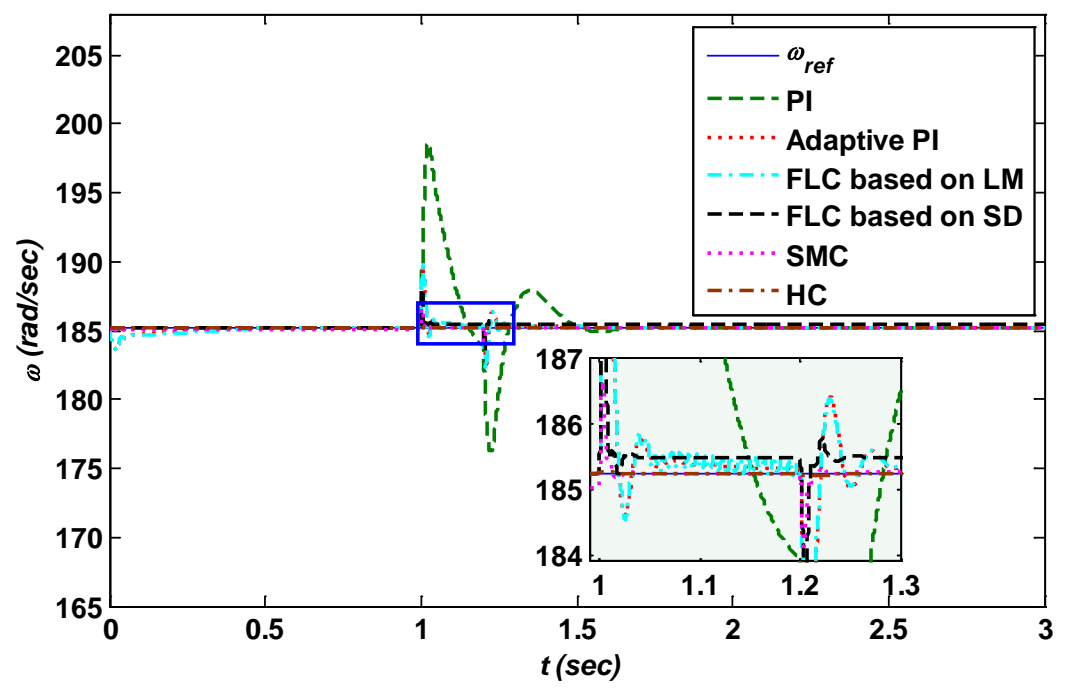

Figure 20. Overvoltage.

The fault tolerant capability of the design control strategies was investigated for overvoltage and under voltage electrical fault perturbation. At $t=1 \mathrm{~s}$ the three phase voltages were maximized and minimized to $150 \%$ and $50 \%$ of the rated values for $200 \mathrm{~ms}$. The PI control strategy shows undershoots of $13.75 \mathrm{rad} / \mathrm{s}$ and $9.25 \mathrm{rad} / \mathrm{s}$, settling times of $t=1.8 \mathrm{~s}$ and $t=1.7 \mathrm{~s}$, and overshoots of $28.75 \mathrm{rad} / \mathrm{s}$ and $13.75 \mathrm{rad} / \mathrm{s}$, respectively, and bulky transient oscillation was noted for undervoltage and overvoltage. The dynamic behavior of adaptive PI, FLC based on LM, FLC based on SD, and SMC generated average settling times of $t=1.62 \mathrm{~s}$ and $t=1.58 \mathrm{~s}$, overshoots of $2.75 \mathrm{rad} / \mathrm{s}$ and $4.75 \mathrm{rad} / \mathrm{s}$, and undershoots of $2.25 \mathrm{rad} / \mathrm{s}$ and $5.25 \mathrm{rad} / \mathrm{s}$, for overvoltage and undervoltage faults, respectively, and comparatively less oscillation for overvoltage and undervoltage. The overvoltage and undervoltage faults of the HC scheme provides settling times of $t=1.35 \mathrm{~s}$ and $t=1.4 \mathrm{~s}$, overshoots of $0.02 \mathrm{rad} / \mathrm{s}$ and $0.05 \mathrm{rad} / \mathrm{s}$, and undershoots of $0.03 \mathrm{rad} / \mathrm{s}$ and $0.1 \mathrm{rad} / \mathrm{s}$, respectively.

\subsection{Load Disturbances in Presence of Speed Variation}

The robustness of the designed control schemes were successfully validated for low speed variation and the results are shown in Figure 21. The speed was reduced to half (92.62 rad/s) along with load disturbance at $t=1 \mathrm{~s}$. The non-minimum phase behavior of the PI controller produced an overshoot of $7.06 \mathrm{rad} / \mathrm{s}$ and undershoot of $25.625 \mathrm{rad} / \mathrm{s}$. The speed settled slowly after $t=1.5 \mathrm{~s}$. Furthermore, the simulation results confirm slow convergence, high transient oscillation, and high SSE of the PI control strategy. The responses of adaptive PI, FLC based on LM, FLC based on SD, and SMC were almost the same with settling time of $t=1.4 \mathrm{~s}$, average overshoot of $3.05 \mathrm{rad} / \mathrm{s}$, and undershoot of $3.15 \mathrm{rad} / \mathrm{s}$. The chattering phenomena in the SMC resulted in large oscillations. Moreover, HC strategies provided an overshoot of $0.04 \mathrm{rad} / \mathrm{s}$ that settled at $t=1.4 \mathrm{~s}$ and $0.08 \mathrm{rad} / \mathrm{s}$ undershoot with negligible oscillation. The tracking error for the dynamic response of the speed loop is presented in Figure 22. Among the designed controllers, the PI control strategy showed sensitivity, large slow convergence, and oscillation to load variation. However, the FLC based on LM algorithm, FLC based on SD technique, SMC, and HC (Adaptive Sliding Mode Controller (ASMC)) provided allowable sensitivity, less oscillation, and fast convergence when compared to PI. 


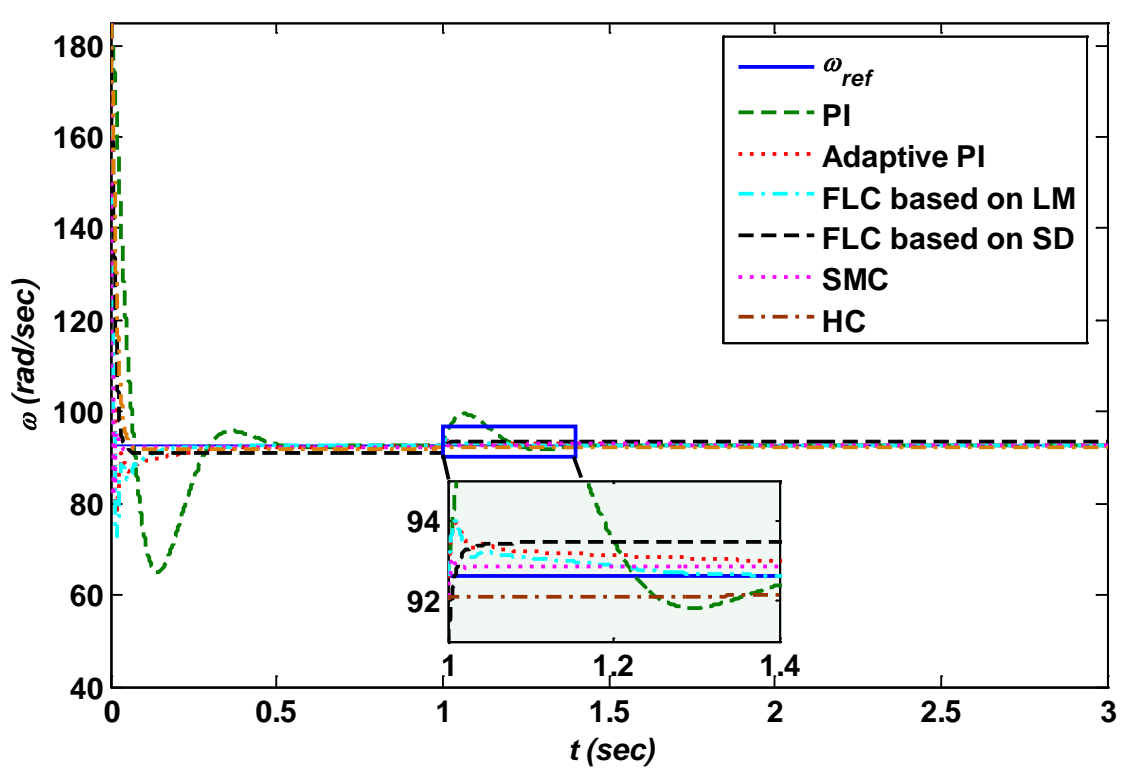

Figure 21. Load disturbances in presence of speed variation.

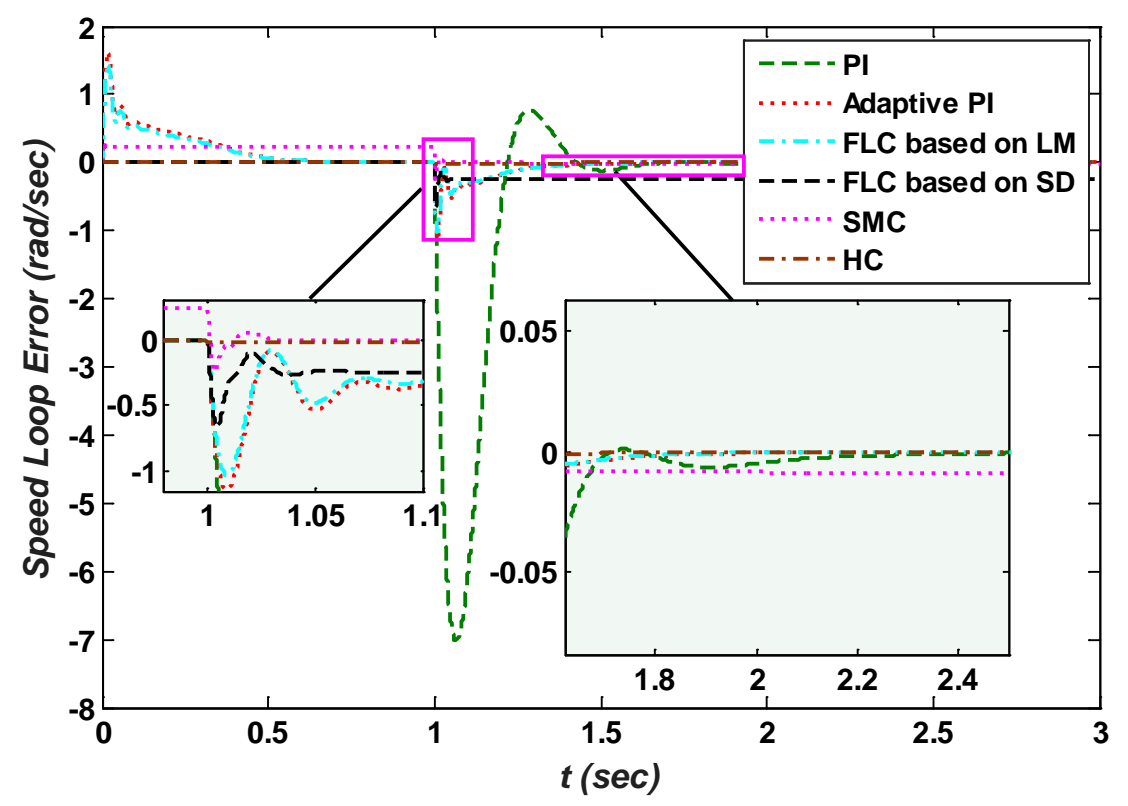

Figure 22. The speed loop error response for designed control schemes.

\subsection{Parameter and Load Variations}

The step-change in parameters generated the worst-case scenario for the motor under IFOC. The variation in the parameters was as follows: rotor resistance $R_{r}$ was $200 \%$ of rated value, mutual inductance $L_{m}$ was $80 \%$ of rated value, inertia $J_{e q}$ to was $130 \%$ of rated value, $T_{L}$ was $50 \%$ of rated value, $R_{S}$ was $120 \%$ of rated value, stator inductance $L_{s}$ was $80 \%$ of rated value, and rotor inductance $L_{r}$ was $90 \%$ of rated value, at time $t=1 \mathrm{~s}$ as presented in Figure 23. In comparison to traditionally tuned PI controllers, the FLC based on LM, FLC based on SD, SMC, and HC provide smooth, robust, permissible overshoot with faster response, rise time, and settling time for the parameter uncertainties and load disturbances as presented in Figure 23. 


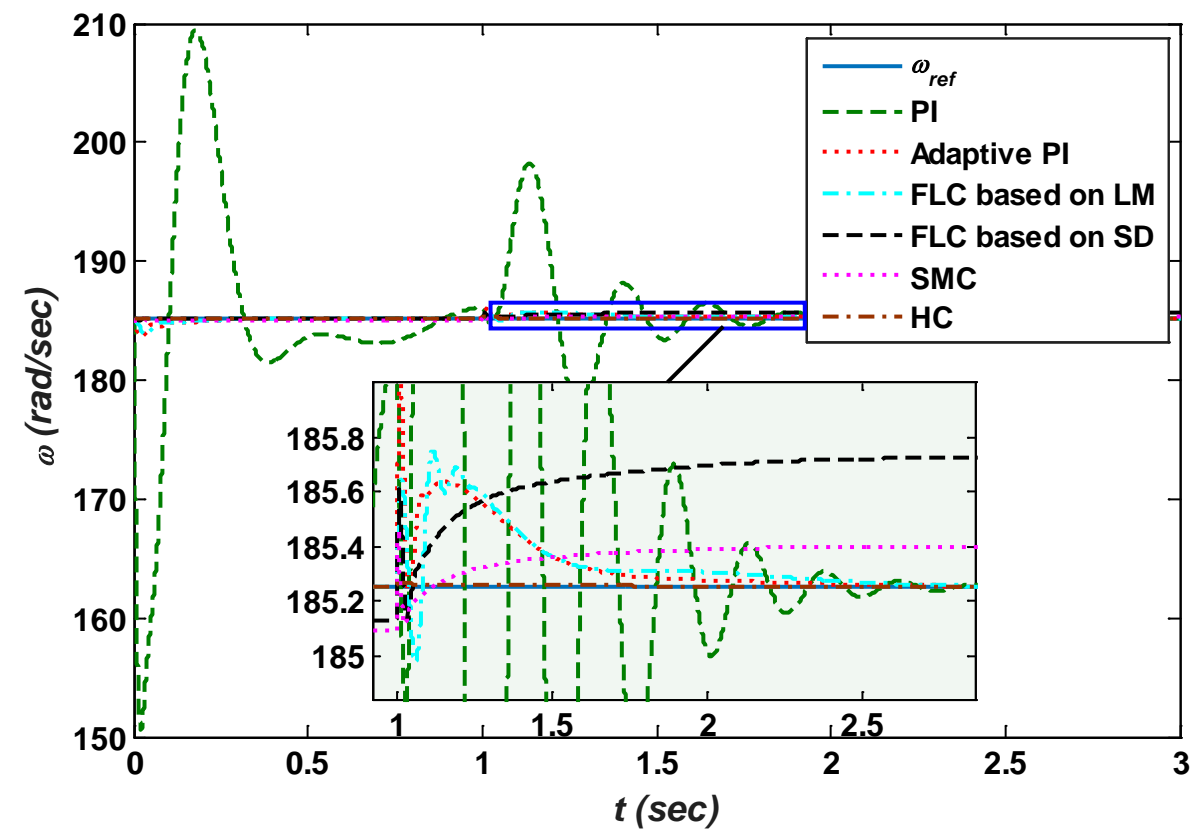

Figure 23. The speed loop parameter variations.

The designed control scheme's performance is critically and analytically compared with recent literature in Table 2. Additionally, the dominant features are guaranteed in regards to load disturbances, parameter variation, chattering phenomena, electrical faults perturbations, and robustness for the proposed control scheme. Moreover $\sqrt{ }$ defines presence and $\times$ defines deficiency of the stated property.

Table 2. Comparison of the designed control strategies with the literature.

\begin{tabular}{cccccccc}
\hline Ref. & CS & IFOC & PV & LV & EFP & CP & R \\
\hline$[1]$ & ADSMCS & $\sqrt{ }$ & $\sqrt{ }$ & $\sqrt{ }$ & $\times$ & $\sqrt{ }$ & $\sqrt{ }$ \\
{$[4]$} & NF and PI & $\sqrt{ }$ & $\sqrt{ }$ & $\times$ & $\times$ & $\sqrt{ }$ & $\sqrt{ }$ \\
{$[19]$} & FSM and PI & $\sqrt{ }$ & $\times$ & $\sqrt{ }$ & $\times$ & $\times$ & $\sqrt{ }$ \\
{$[20]$} & ASMC & $\sqrt{ }$ & $\sqrt{ }$ & $\sqrt{ }$ & $\times$ & $\times$ & $\sqrt{ }$ \\
{$[30]$} & FL and PI & $\sqrt{ }$ & $\sqrt{ }$ & $\sqrt{ }$ & $\times$ & $\times$ & $\times$ \\
{$[31]$} & AFSMC and PI & $\sqrt{ }$ & $\sqrt{ }$ & $\sqrt{ }$ & $\times$ & $\times$ & $\sqrt{ }$ \\
\hline \multirow{6}{*}{ Pur Work } & PI & $\sqrt{ }$ & $\sqrt{ }$ & $\sqrt{ }$ & $\sqrt{ }$ & $\sqrt{ }$ & $\times$ \\
& Adaptive PI & $\sqrt{ }$ & $\sqrt{ }$ & $\sqrt{ }$ & $\sqrt{ }$ & $\times$ & $\sqrt{ }$ \\
& FLC based on LM & $\sqrt{ }$ & $\sqrt{ }$ & $\sqrt{ }$ & $\sqrt{ }$ & $\times$ & $\sqrt{ }$ \\
& SLC based on SD & $\sqrt{ }$ & $\sqrt{ }$ & $\sqrt{ }$ & $\sqrt{ }$ & $\times$ & $\sqrt{ }$ \\
& SMC & $\sqrt{ }$ & $\sqrt{ }$ & $\sqrt{ }$ & $\sqrt{ }$ & $\times$ & $\sqrt{ }$ \\
\hline
\end{tabular}

CS: Control strategies, PV: Parameter Variation, IFOC: Indirect Field Oriented Controller, EFP: Electrical Faults Perturbations, LV: Load Variation, CP: Chattering Phenomena, R: Robustness, ADSMCS: Adaptive Dynamic Sliding Mode Control System, NFC: Neuro-Fuzzy Controller, PI: Proportional and Integral, FSM: Fuzzy Sliding Mode, ASMC: Adaptive Sliding Mode Controller, AFSMC: Adaptive Fuzzy Sliding Mode Controller, FLC: Fuzzy Logic Controller, LM: Levenberg-Marquardt, SD: Steepest Descent, SMC: Sliding Mode Controller, HC: Hybrid Controller.

\section{Conclusions and Future Work}

Optimal control strategies such as Adaptive PI, FLC based on LM and SD, SMC, and HC are designed for the speed loop of the IFOC IM drive that ensures the robustness in the presence of load disturbance, speed variation, electrical fault perturbations, and parameter uncertainties. The designed adaptive PI control strategy results illustrates better dynamic response with a rapid settling time and low overshoot for sudden changes of the IFOC IM drive. Since the exact system model is not 
required, the FLC based on LM and SD techniques is stable, robust, and insensitive to operating conditions and parameter variations. The SMC is a powerful non-linear control scheme that assures a remarkably fast dynamic response, robustness, external disturbance rejection, and immunity to parameter variation. The proposed HC incorporates the favorable characteristics of the SMC and PI-fuzzy by assuring fast dynamic response, global stability, and reduced chattering in the torque and speed loop. The performance of the designed control schemes is superior to that of fine-tuned PI control schemes for parameter and load variation. Furthermore, the order at which the best performance for the proposed controllers is noted for HC, FLC based on LM, SMC, FLC based on SD, and adaptive PI. The dominant features of the designed optimal control approach in comparison with the conventionally tuned PI control strategies are: low overshoot, rise time, and settling time, fast dynamic response, less sensitivity to load disturbances and electrical fault perturbations, robust to speed variations and parameter uncertainties, reduced chattering, low voltage dips, and less power consumption. The fault tolerant capability of the design control strategy is also guaranteed in the simulation result.

In the near future, the proposed control schemes will be extended to position, flux $\left(i_{s d}\right)$, and torque $\left(i_{s q}\right)$ control loops for IFOC IM. Moreover, the simulated results will be validated using the hardware TMS320F28335 DSP board or DSPACE (Delfino Texas Instrument, Mansfield, TX, USA). Furthermore, Adaptive L1, H-infinity, High Order Adaptive SMC, and Feedback Linearization control strategies will be implemented. Additionally, the proposed optimal control schemes will be effectively adopted for a Doubly Fed Induction Motor (DFIM) and a Doubly Fed Induction Generator (DFIG), and the outcomes will be experimentally validated for robustness. Instead of MOSFET and IGBT switching devices (Delfino Texas Instrument, Mansfield, TX, USA), Silicon Carbide (SiC) and Gallium Arsenide $(\mathrm{GaN})$ will be used to enhance the efficiency of the inverter.

Author Contributions: K.Z., W.U.D., and M.A.K. proposed the main idea of the paper. K.Z. implemented the mathematical derivations, simulation verifications, and analyses. The paper was written by K.Z. and was revised by A.K., U.Y., T.D.C.B. and H.J.K. All the authors were involved in preparing the final version of this manuscript. All work was supervised by H.J.K.

Funding: This Research was supported by BK21PLUS, Creative Human Resource Development Program for IT Convergence.

Conflicts of Interest: The authors declare no conflict of interest.

\section{Appendix}

Table A1. Machine nominal parameters.

\begin{tabular}{cc}
\hline IM Parameters & Values \\
\hline Rated Power & $3 \mathrm{HP} / 2.4 \mathrm{~kW}$ \\
Phases & 3 \\
Line Voltage & $460 \mathrm{~V}(\mathrm{~L}-\mathrm{L}, \mathrm{rms})$ \\
System Frequency & $60 \mathrm{~Hz}$ \\
Full Load Slip & $1.72 \%$ \\
Number of Poles & 4 \\
Switching Frequency & $20 \mathrm{kHz}$ \\
Stator Resistance & $1.7 \Omega$ \\
Stator Leakage Resistance & $5.25 \Omega$ \\
Rotor Resistance & $1.34 \Omega$ \\
Rotor Leakage Resistance & $4.57 \Omega$ \\
Moment of Inertia & $70 \mathrm{~kg} \cdot \mathrm{m}^{2}$ \\
Mutual Inductance & $139 \Omega$ \\
Full Load Current & $4 \mathrm{~A}$ \\
Full Load Speed & $1750 \mathrm{rpm}$ \\
\hline
\end{tabular}


Table A2. Control schemes' constants.

\begin{tabular}{ccc}
\hline Control Strategies & Parameter & Values \\
\hline PI & $k_{p}$ & 0.2446 \\
& $k_{i}$ & 3.5298 \\
\hline \multirow{2}{*}{ Adaptive PI } & $k_{1}$ & 0.5 \\
& $k_{2}$ & 0.75 \\
\hline \multirow{2}{*}{ FLC based on LM } & $c_{1}$ & 0.2 \\
& $c_{2}$ & 0.3 \\
& $\sigma_{1}$ & 0.11 \\
& $\sigma_{2}$ & 0.33 \\
& $b_{1}$ & 0.7 \\
& $b_{2}$ & 0.01 \\
& $\lambda$ & 0.57 \\
FLC based on Steepest Descent & $\mu$ & 0.66 \\
\hline \multirow{2}{*}{ Sliding Mode } & $\alpha_{1}$ & 0.0001 \\
& $\alpha_{2}$ & 0.00199 \\
\hline \multirow{2}{*}{ Hybrid } & $k$ & $0.2-1.5$ \\
& $\beta$ & $0.5-4$ \\
\hline
\end{tabular}

\section{References}

1. Tosifian, M.H.; Nazarzadeh, J. A detailed model of disk type linear induction machines. Int. Trans. Electr. Energy Syst. 2015, 25, 1736-1747. [CrossRef]

2. Uddin, M.N.; Huang, Z.R.; Hossain, A.B.M.S. Development and Implementation of a Simplified Self-Tuned Neuro-Fuzzy-Based IM Drive. IEEE Trans. Ind. Appl. 2014, 50, 51-59. [CrossRef]

3. Jain, J.K.; Ghosh, S.; Maity, S. A Numerical Bifurcation Analysis of Indirect Vector-Controlled Induction Motor. IEEE Trans. Control Syst. Technol. 2018, 26, 282-290. [CrossRef]

4. Kan, J.; Zhang, K.; Wang, Z. Indirect vector control with simplified rotor resistance adaptation for induction machines. IEEE Trans. Power Electron. 2015, 8, 1284-1294. [CrossRef]

5. Pereira, W.C.A.; Oliveira, C.M.R.; Santana, M.P.; Almeida, T.E.P.; Castro, A.G.; Paula, G.T.; Aguiar, M.L. Improved Sensorless Vector Control of Induction motor Using Sliding Mode Observer. IEEE Lat. Am. Trans. 2016, 14, 3110-3116. [CrossRef]

6. Amezquita-Brooks, L.; Liceaga-Castro, J.; Liceaga-Castro, E. Speed and position controllers using indirect field-oriented control: A classical control approach. IEEE Trans. Ind. Electron. 2014, 61, 1928-1943. [CrossRef]

7. Habibullah, M.; Lu, D.D.-C.; Xiao, D. Muhammed Fazlur Rahman: 'Predictive torque control of induction motor sensorless drive fed by a 3L-NPC inverter'. IEEE Trans. Ind. Inf. 2017, 13, 60-70. [CrossRef]

8. Guzinski, J.; Abu-Rub, H. Speed sensorless induction motor drive with predictive current controller. IEEE Trans. Ind. Electron. 2011, 60, 272-282. [CrossRef]

9. Teja, A.V.R.; Chakraborty, C.; Maiti, S.; Hori, Y. A new model reference adaptive controller for four quadrant vector controlled induction motor drives. IEEE Trans. Ind. Electron. 2012, 59, 3757-3767. [CrossRef]

10. Uddin, M.N.; Nam, S.W. Development and implementation of a nonlinear-controller-based IM drive incorporating iron loss with parameter uncertainties. IEEE Trans. Ind. Electron. 2009, 56, 1263-1272. [CrossRef]

11. Konstantopoulos, G.C.; Alexandridis, A.T.; Mitronikas, E.D. Bounded nonlinear stabilizing speed regulators for VSI-Fed induction motors in field-oriented operation. IEEE Trans. Control Syst. Technol. 2014, 22, 1112-1121. [CrossRef]

12. Qiao, Z.; Shi, T.; Wang, Y.; Yan, Y.; Xia, C.; He, X. New sliding mode observer for position sensorless control of permanent-magnet synchronous motor. IEEE Trans. Ind. Electron. 2013, 60, 710-719. [CrossRef]

13. Barambones, O.; Alkorta, P. Position Control of the Induction Motor Using an Adaptive Sliding-Mode Controller and Observers. IEEE Trans. Ind. Electron. 2014, 61, 6556-6565. [CrossRef] 
14. Leu, V.Q.; Choi, H.H.; Jung, J.-W. Fuzzy sliding mode speed controller for PM synchronous motors with a load torque observer. IEEE Trans. Power Electron. 2012, 27, 1530-1539. [CrossRef]

15. Zaky, M.S.; Metwaly, M.K. A Performance Investigation of a Four Switch Three-Phase Inverter-Fed IM Drives at Low Speeds Using Fuzzy Logic and PI Controllers. IEEE Trans. Power Electron. 2017, 32, 3741-3753. [CrossRef]

16. Zerikat, M.; Mechernene, A.; Chekroun, S. High-performance sensorless vector control of induction motor drives using artificial intelligent technique. Eur. Trans. Electr. Power 2011, 21, 787-800. [CrossRef]

17. Fu, X.; Li, S. A novel neural network vector control technique for induction motor drive. IEEE Trans. Energy Convers. 2015, 30, 1428-1437. [CrossRef]

18. Farasat, M.; Trzynadlowski, A.M.; Fadali, M.S. Efficiency improved sensorless control scheme for electric vehicle induction motors. IET Electr. Syst. Transp. 2014, 4, 122-131. [CrossRef]

19. Su, K.-H.; Kung, C.-C. Supervisory enhanced genetic algorithm controller design and its application to decoupling induction motor drive. IEEE Electr. Power Appl. 2005, 152, 1015-1026. [CrossRef]

20. Benlaloui, I.; Drid, S.; Chrifi-Alaoui, L.; Ouriagli, M. Implementation of a new MRAS speed sensorless vector control of induction machine. IEEE Trans. Energy Convers. 2015, 30, 588-595. [CrossRef]

21. Basilio, J.C.; Silva, J.A., Jr.; Rolim, L.G.B.; Moreira, M.V. $H_{\alpha}$ design of rotor flux-oriented current-controlled induction motor drives: Speed control, noise attenuation and stability robustness. IET Control Theory Appl. 2010, 3, 2491-2505. [CrossRef]

22. Arun Kumar, R.; Febin Daya, J.L. A novel self-Tuning fuzzy based PID controller for speed control of induction motor drive. In Proceedings of the International Conference on Control Communication and Computing (ICCC), Thiruvananthapuram, India, 13-15 December 2013; pp. 62-66.

23. Yue, Y.; Lin, Y.; Yin, Z. A novel induction motor with fuzzy sliding-mode control. In Proceedings of the IEEE Conference on Chinese Control (CCC), Yantai, China, 22-24 July 2011; pp. 1835-1838.

24. Mohan, N. Advance Electric Drives Analysis, Control and Modeling Using SIMULINK; MNPERE: Minneapolis, MN, USA, 2001; ISBN 978-1-118-48548-4.

25. Zeb, K.; Uddin, W.; Haider, A.; Belal, S.; Mehmood, C.A.; Khan, M.A.; Kim, H.J. Robust speed regulation of indirect vector control induction motor using fuzzy logic controllers based on optimization algorithms. Electr. Eng. 2018, 100, 787-802. [CrossRef]

26. Harb, A.M.; Smadi, I.A. An Approach to Fuzzy Control for a Class of Nonlinear Systems: Stability and Design Issues. Int. J. Model. Simul. 2015, 25, 106-111. [CrossRef]

27. Wilamowski, B.M.; Yu, H. Improved computation for Levenberg Marquardt training. IEEE Trans. Neural Netw. 2010, 21, 930-937. [CrossRef] [PubMed]

28. Zeb, K.; Ali, Z.; Saleem, K.; Uddin, W.; Javed, M.A.; Christofides, N. Indirect field-oriented control of induction motor drive based on adaptive fuzzy logic controller. Electr. Eng. 2017, 99, 803-815. [CrossRef]

29. Dominguez, J.R.; Mora-Soto, C.; Ortega-Cisneros, S.; Panduro, J.J.R.; Loukianov, A.G. Copper and core loss minimization for induction motors using high-order sliding-mode control. IEEE Trans. Ind. Electron. 2012, 59, 2877-2889. [CrossRef]

30. Dominguez, J.R. Discrete-Time Modeling and Control of Induction Motors by Means of Variational Integrators and Sliding Modes-Part I: Mathematical Modeling. IEEE Trans. Ind. Electron. 2015, 62, 5393-5401. [CrossRef]

31. Hannan, M.A.; Ali, J.A.; Mohamed, A.; Amirulddin, U.A.U.; Tan, N.M.L.; Uddin, M.N. Quantum-Behaved Lightning Search Algorithm to Improve Indirect Field-Oriented Fuzzy-PI Control for IM Drive. In Proceedings of the 2017 IEEE Industry Applications Society Annual Meeting, Cincinnati, OH, USA, 1-5 October 2017.

32. Saghafinia, A.; Ping, H.W.; Uddin, M.N.; Gaeid, K.S. Adaptive Fuzzy Sliding-Mode Control into Chattering-Free IM Drive. IEEE Trans. Ind. Appl. 2015, 51, 692-702. [CrossRef]

(C) 2018 by the authors. Licensee MDPI, Basel, Switzerland. This article is an open access article distributed under the terms and conditions of the Creative Commons Attribution (CC BY) license (http:// creativecommons.org/licenses/by/4.0/). 